\title{
Research on the Impact of Wind Angles on the Residential Building Energy Consumption
}

\author{
Zou Huifen, Yang Fuhua, and Zhang Qian \\ School of Municipal and Environmental Engineering, Shenyang Jianzhu University, Shenyang 110168, China \\ Correspondence should be addressed to Zou Huifen; jerry_zou@163.com
}

Received 15 May 2014; Accepted 14 July 2014; Published 27 August 2014

Academic Editor: Jun Liu

Copyright ( 2014 Zou Huifen et al. This is an open access article distributed under the Creative Commons Attribution License, which permits unrestricted use, distribution, and reproduction in any medium, provided the original work is properly cited.

\begin{abstract}
Wind angles affect building's natural ventilation and also energy consumption of the building. In winter, the wind direction in the outdoor environment will affect heat loss of the building, while in summer the change of wind direction and speed in the outdoor environment will affect the building's ventilation and indoor air circulation. So, making a good deal with the issue of the angle between local buildings and the dominant wind direction can effectively solve the winter and summer ventilation problems. Thereby, it can enhance the comfort of residential person, improve indoor air quality, solve heat gain and heat loss problems in winter and summer in the severely cold and cold regions, and reduce building energy consumption. The simulation software CFD and energy simulation software are used in the paper. South direction of the building is the prototype of the simulation. The angle between the direction of the building and the outdoor environment wind is changed sequentially. Energy consumption under different wind angle conditions is compared with each other. Combined with natural ventilation under various wind angles, the paper gives the best recommended solution of building direction in Shenyang.
\end{abstract}

\section{Introduction}

In recent years, with the rapid economic development and the accelerated process of urbanization, the construction area of urban housing is increasing. It is expected that, at the end of 2020, China's urban housing construction area will reach 26.1 billion $\mathrm{m}^{2}$ [1]. While there is a vigorous development in residential construction, total building energy consumption is also increasing year by year. In 1970 s, $10 \%$ of the total energy consumption is the building energy consumption while, in $2013,27 \%$ to $30 \%$ of total energy consumption is the building energy consumption [2]. The contradiction between the shortage of energy supply and the increasing energy consumption becomes to be a huge obstacle which constrains the sustainable economic development. So, developing the use of energy-efficient buildings and improving the comfort of the living environment are the principal thing to be solved.

By using air energy of the nature, natural ventilation generally cools the building, reduces the indoor temperature, adds fresh and clean natural air to the indoor area, and takes away the damp polluted air. Indoor air flow enhances convection and evaporation cooling of the body, which is conducive to physical and mental health of the human body [3]. Natural ventilation not only is an important passive building energy-saving technology, but also represents a healthy, natural lifestyle.

While wind angles affect buildings' natural ventilation, they also affect energy consumption of the building. In winter, the wind direction in the outdoor environment will affect heat loss of the building, while in summer the change of wind direction and speed in the outdoor environment will affect the building's ventilation and indoor air circulation [4]. So, making a good deal with the issue of the angle between local buildings and the dominant wind direction can effectively solve the winter and summer ventilation problems. Thereby, it can enhance the comfort of residential person, improve indoor air quality, solve heat gain and heat loss problems in winter and summer in the severely cold and cold regions, and reduce building energy consumption [5]. The simulation software CFD and energy simulation software are used in the paper. South direction of the building is the prototype of the simulation. The angle between the direction 
of the building and the outdoor environment wind is changed sequentially. Energy consumption under different wind angle conditions is compared with each other. Combined with natural ventilation under various wind angles, the paper gives the best recommended solution of building direction in Shenyang.

\section{The Principle of Natural Ventilation}

As one of the oldest and the most energy-efficient ventilation ways, the natural ventilation is the basic method for enhancing the indoor thermal comfort, one of the main methods for improving indoor air quality, and one of the main measures to reduce buildings' energy consumption [6]. Natural ventilation generally refers to indoor air flow generated by purposeful opening, which will improve the indoor environment. This flow is directly affected by the pressure of the outer surface of the building, the wind speed distribution, different opening positions, and the opening characteristics. Pressure on the surface of the building is divided into wind pressure and hot pressing. Hot pressing is mainly formed by the temperature difference between indoors and outdoors. Wind pressure is mainly the effect of the static pressure difference between indoors and outdoors, which is caused by the role of the outdoor air working on the external structure of the building [7].

2.1. Natural Ventilation under the Hot Action. When there exists a heat source in the building, the indoor air is heated, its density decreases, and the air floats upwards, which causes higher air pressure of the upper portion in the building construction than that of the outside. Thus, indoor air flows through the opening to the outside, while continuous inflow of air at the bottom of the building fills up the space let out by upper outflow of air at the same time. The continuous air flow forms the natural ventilation under the hot-pressing action. According to the height difference between positions and different orifices, hot ventilation can be divided into "hole" ventilation (see Figure 1) and the "holes" ventilation (see Figure 2) [8].

The formula of the hot action is

$$
\Delta P=\alpha \rho_{0} H\left(T_{i}-T_{o}\right)
$$

where $\Delta P$ is the thermal pressure of openings on both sides, $\mathrm{Pa} ; \alpha$ is expansion coefficients of air, $\mathrm{K}^{-1} ; \rho_{0}$ is outdoor air density, $\mathrm{Kg} / \mathrm{m}^{3} ; g$ is acceleration of gravity, $\mathrm{m} / \mathrm{s}^{2} ; H$ is opening vertical height, $\mathrm{m} ; T_{i}$ is the average indoor air temperature, $\mathrm{K}$; and $T_{o}$ is the average outdoor air temperature, K.

Thus, the role of natural ventilation under the hot effect depends on the vertical height of the opening of the building and the temperature difference between the inside and the outside of the building.

2.2. Natural Ventilation under the Wind Pressure. When the outdoor air flows through the building, the phenomenon called "flowing around" will take place and air flow parallel motion can resume in the process of flowing around after

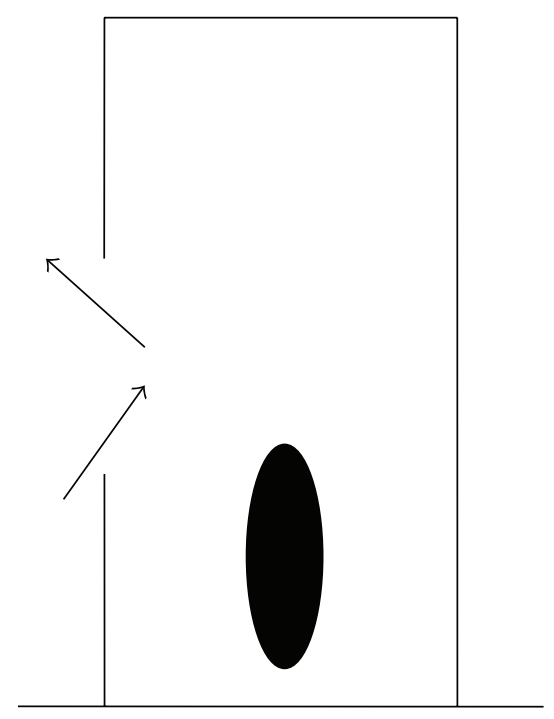

FIGURE 1: "Hole" ventilation under the hot action.

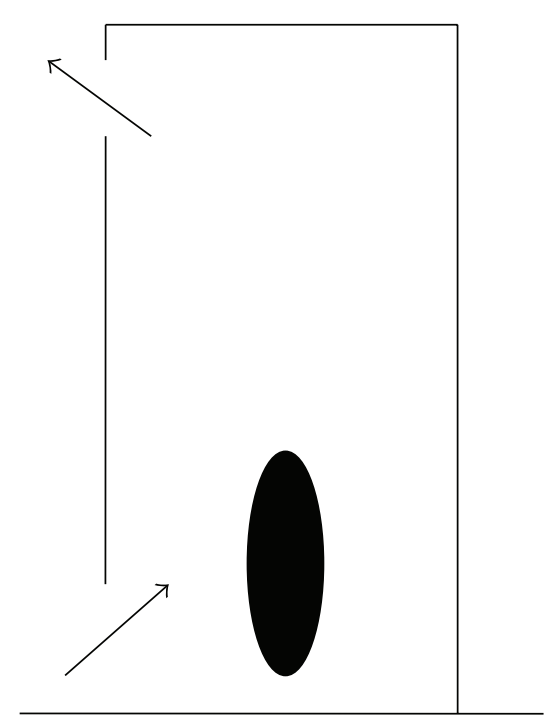

FIGURE 2: "Holes" ventilation under the hot action.

a certain distance. Due to the blocking of the building, the distribution of air pressure around the building will change. Because of the obstruction of the airflow, the reduced dynamic pressure, and the increasing static pressure, a positive pressure area will form in the windward side of the building. Because of local vortex and reduced static pressure, negative pressure area will form on the top and the back of the building. Compared with undisturbed air flow far from the building, the change of the static pressure on the surface of a building is called pressure under the wind action [9].

The wind pressure distribution around a building is related to the geometry of the building and the wind direction and speed outdoors. When the wind direction is constant 


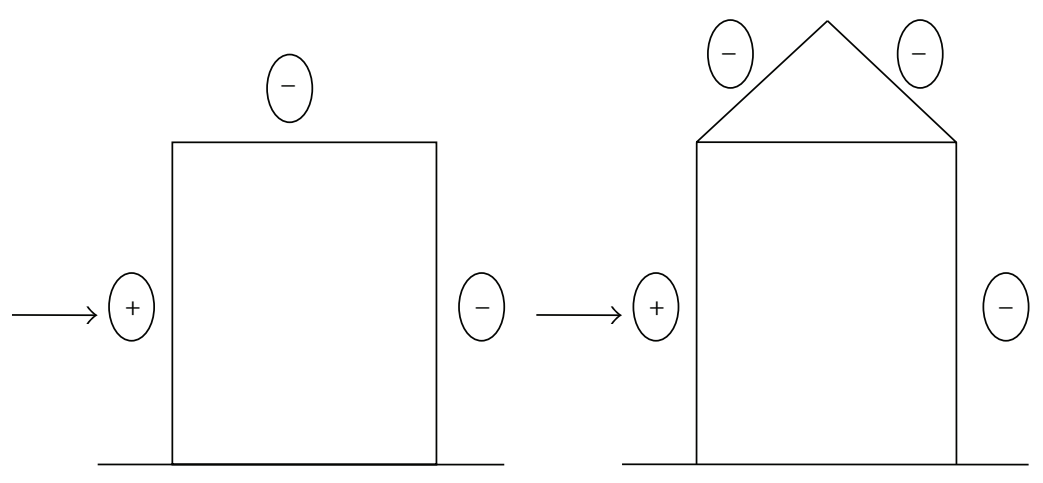

(a)

(b)

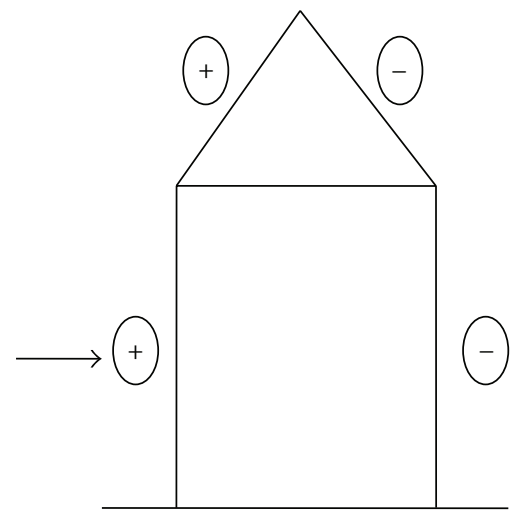

(c)

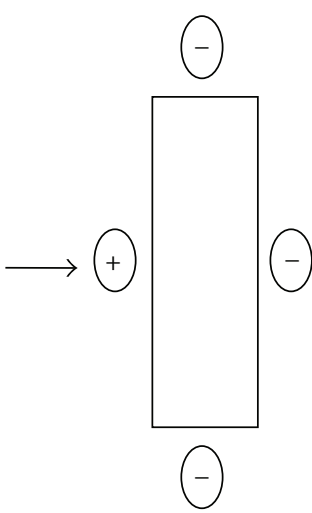

(d)

Figure 3: Pressure distributions under different roof heights. (a) Flat roof building (vertical section), (b) pitched roof construction with $30^{\circ}$ slope, (c) pitched roof construction with $45^{\circ}$ slope, and (d) building plans.

outdoors, the value of a pressure point of building envelope structure can be expressed as follows [10]:

$$
P=K \frac{\rho_{o} v_{o}^{2}}{2}
$$

where $P$ is the value of a pressure point on the building envelope structure, $\mathrm{Pa} ; K$ is aerodynamic coefficient; $v_{o}$ is outdoor air flow rate, $\mathrm{m} / \mathrm{s} ; \rho_{o}$ is outdoor air flow rate, $\mathrm{kg} / \mathrm{m}^{3}$.

The aerodynamic coefficient $K$ of different shapes of buildings is different at different wind directions. When the $K$ value is positive, the wind pressure value of the point is positive, and when the $K$ value is negative, the wind pressure value of the point is negative. Under the action of wind pressure, the wind enters from the positive pressure side and gets out from the negative pressure side. Figure 3 represents the wind pressure distributions under different roof heights [11]. In any case, the wind pressure is negative near the surface of flat roofs and irrelevant to the wind direction, and its variation is very small. When the pitched roof's slope is small, both the front and the back have negative pressure while, with the increase of slope, the front roof has positive pressure, and the back roof has negative pressure.

In the surface layer, outdoor wind speed of $v$ has larger variation with height; the average wind speed with the height variation can be described by exponential function, and its expression is shown as follows:

$$
v_{o}=v_{10}\left(\frac{H}{10}\right)^{\alpha},
$$

where $v_{o}$ is outdoor air velocity at the height of $H, \mathrm{~m} / \mathrm{s} ; v_{10}$ is outdoor wind speed at the standard height $(10 \mathrm{~m}), \mathrm{m} / \mathrm{s} ; H$ is height of any point, $\mathrm{m} ; \alpha$ is roughness coefficient of surface, in a built-up city center $\alpha=0.20$, in offshore island and desert $\alpha=0.12$, and in rural and suburban $\alpha=0.16$.

\subsection{Natural Ventilation under the Action of Wind Pressure and} Heat Pressure. In most cases, building natural ventilation is not caused by a factor, but by the factors of wind pressure and heat pressure together. Their functions are varying and their contributions to the whole building's natural ventilation are different. When the building is bearing heat and wind pressure at the same time, the internal and external pressure difference of each window hole is equal to the sum of the pressure difference of inside and outside window hole when the building bears the heat pressure and the wind pressure independently [12]. Effect of wind pressure and heat pressure on the natural ventilation in architecture is often inseparable, and the heat pressure of building is relatively stable and easy to implement, but the action of the wind is unstable and is often affected by the building's shape, the 


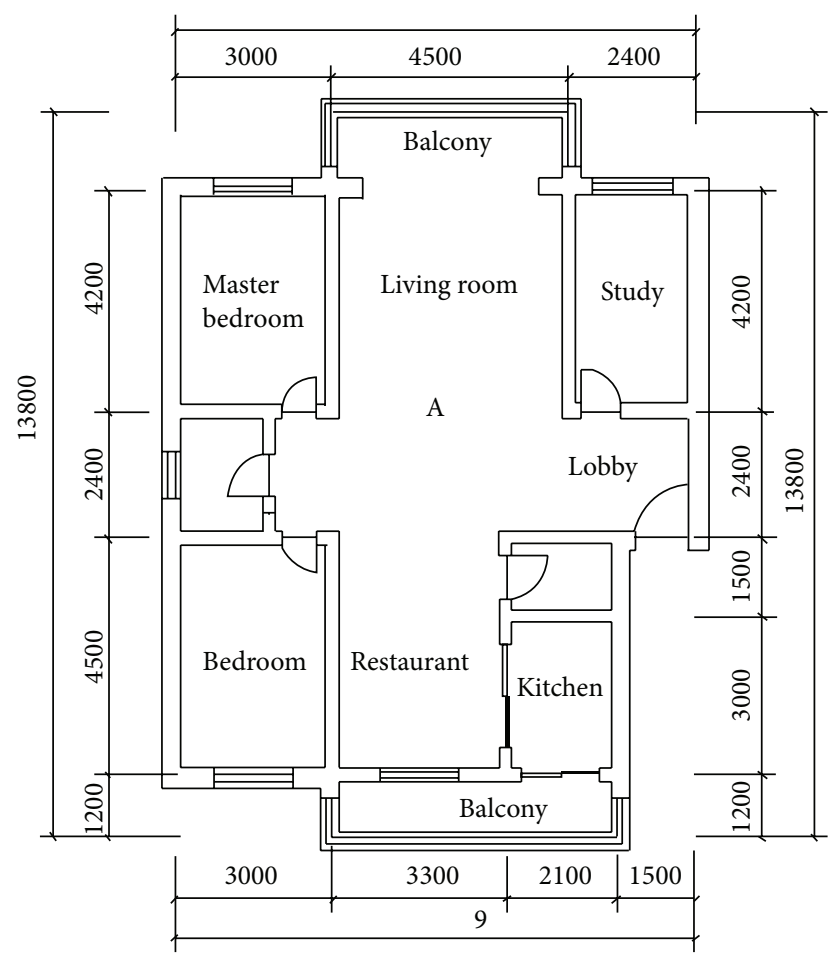

Figure 4: Apartment A.
(2) Simulation of the Flow Field Equations. In fluid mechanics, fluid flow follows three basic laws of conservation of mass, conservation of momentum, and conservation of energy. By the laws of conservation of these, the continuity equation, momentum, and energy equations can be obtained in mathematical research. These equations are expressed as a differential form of the continuity equation $[15,16]$, also known as mass conservation equations, whose differential expression is

$$
\frac{\partial \rho}{\partial t}+\frac{\partial}{\partial x_{i}}\left(\rho u_{i}\right)=0
$$

where $\rho$ is expressed as the density of the fluid and $\mu_{i}$ is expressed as the fluid component along the $i$ direction.

Momentum equation is

$$
\begin{aligned}
& \frac{\partial\left(\rho u_{i}\right)}{\partial t}+\frac{\partial\left(\rho u_{i} u_{j}\right)}{\partial x_{j}} \\
& \quad=-\frac{\partial p}{\partial x_{i}}+\frac{\partial}{\partial x_{j}}\left[\eta\left(\frac{\partial u_{i}}{\partial x_{j}}+\frac{\partial u_{j}}{\partial x_{i}}\right)\right]+\rho \beta\left(T_{0}-T\right) g_{i} .
\end{aligned}
$$

Energy equation is

$$
\frac{\partial(\rho T)}{\partial t}+\frac{\partial\left(\rho u_{j} T\right)}{\partial x_{j}}=\frac{\partial}{\partial x_{j}}\left[\left(\frac{\eta}{\operatorname{Pr}}+\frac{\eta}{\sigma_{k}}\right) \frac{\partial T}{\partial x_{j}}\right]+S_{T},
$$

where $S_{T}$ is expressed as the volume of chemical reaction heat or other heat sources.

Unifying the above formula, it can be expressed as

$$
\frac{\partial}{\partial t}(\rho \varphi)+\operatorname{div}(\rho \bar{u} \varphi)=\operatorname{div}(\Gamma \operatorname{grad} \varphi)+S
$$

where $\varphi$ is expressed as universal variables, which represents $\mu, v, \omega, T$ and other variables. $\Gamma$ represents the diffusion coefficient. $S$ represents the source term. Where $\Gamma$ and $S$ are specific for the corresponding. In the general formula, the above four items represent time, convection term, diffusion, and source terms.

(3) Select Turbulence Model. After the study of turbulence by people for more than a century, now it has a variety of turbulence models, such as Reynolds stress model (RSM), algebraic stress model (ASM), and sticky coefficient model $(\mathrm{EVM})$. Based on solving differential turbulent viscosity coefficient equations, EVM is divided into zero-equation model, one-equation model, and two equation model. Their calculations have small amount and they are very suitable for engineering applications where $k-\varepsilon$ model is most commonly used [17].

$k-\varepsilon$ model is a semiempirical formula model; it is assumed to be a fully developed turbulent flow, and viscosity derived simulate turbulence theory [14]. 


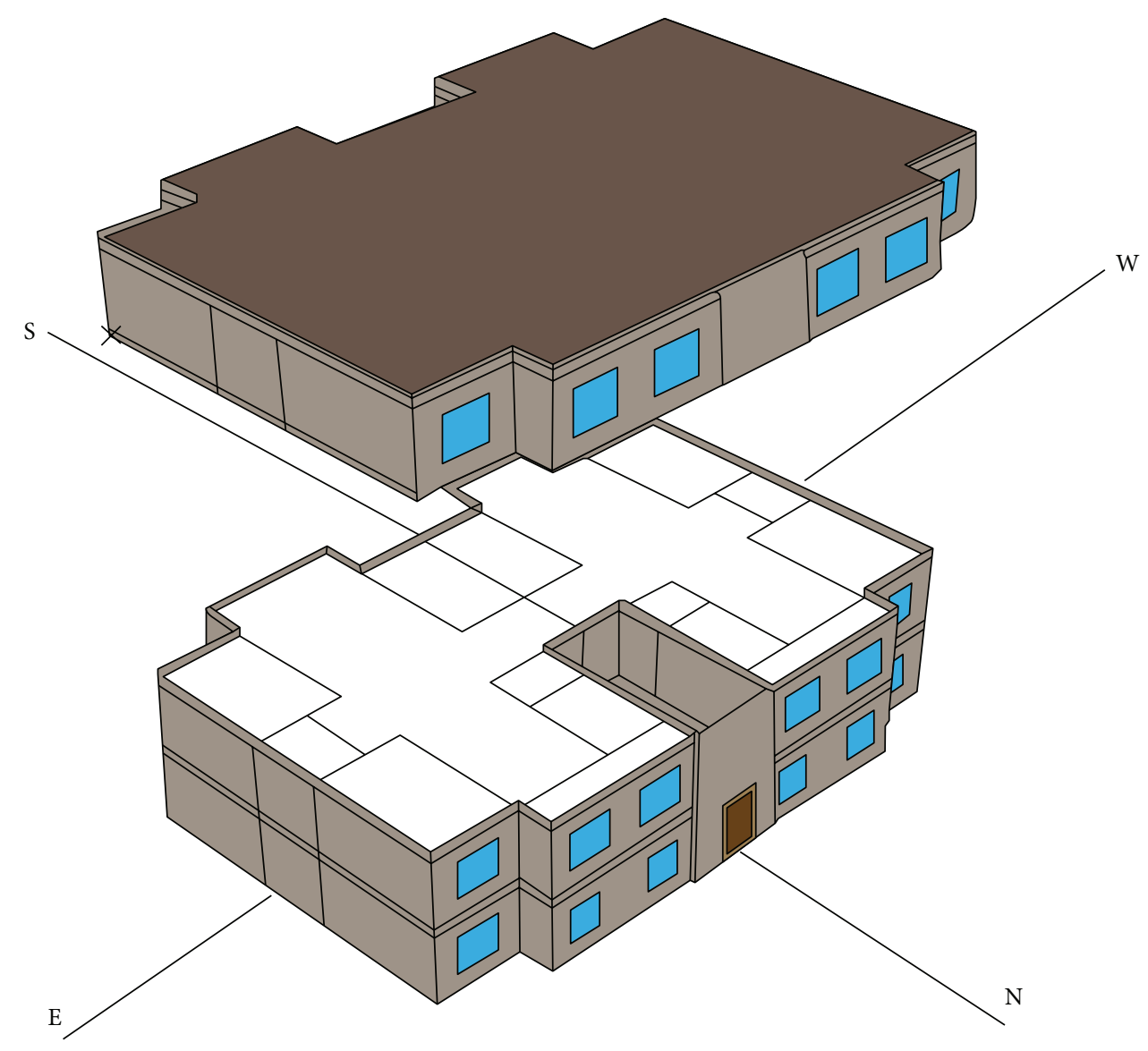

FIgURE 5: Residential building model diagram.

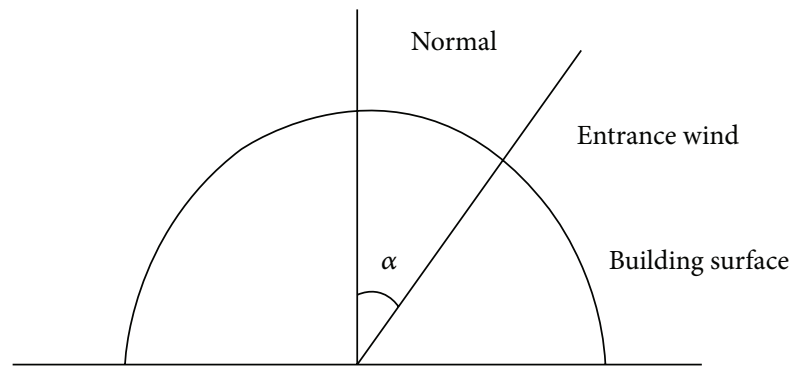

Figure 6: Wind angle.

molecules can be ignored. $K$ equation and $\varepsilon$ equations are as follows:

$$
\begin{aligned}
& \frac{\partial(\rho k)}{\partial t}+\frac{\partial\left(\rho u_{j} k\right)}{\partial x_{j}}=\frac{\partial}{\partial x_{j}}\left(\frac{\eta}{\sigma_{k}}-\frac{\partial k}{\partial x_{i}}\right)+G_{k}+G_{b}-\rho \varepsilon \\
& \frac{\partial(\rho \varepsilon)}{\partial t}+\frac{\partial\left(\rho u_{j} \varepsilon\right)}{\partial x_{j}} \\
& =\frac{\partial}{\partial x_{j}}\left(\frac{\eta}{\sigma_{\varepsilon}}-\frac{\partial \varepsilon}{\partial x_{i}}\right)+\frac{\varepsilon}{k}+\left(c_{1} G_{k}+c_{3} G_{b}-c_{2} \rho \varepsilon\right),
\end{aligned}
$$

(8) Figure 7: The wind speed distribution of the wind angle $\alpha=75^{\circ}$. 


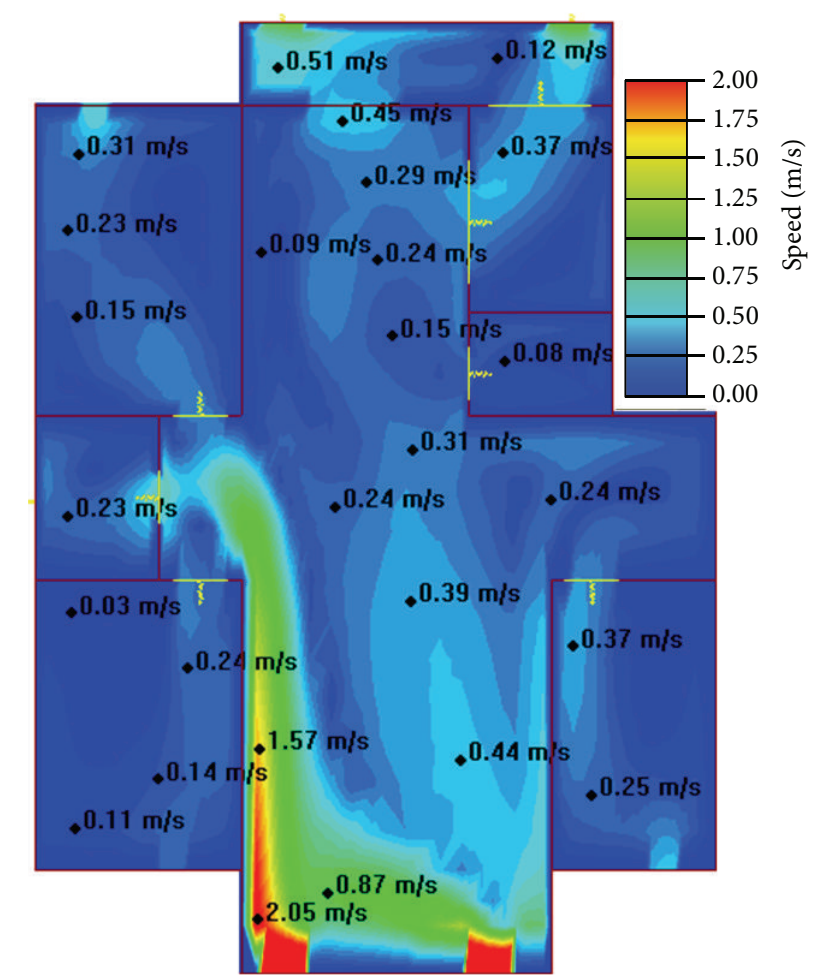

Figure 8: The wind speed distribution of the wind angle $\alpha=60^{\circ}$.

where, $c_{1}, c_{2}$ are the empirical constants and they are 1.44, 1.92 , respectively. $K$ is the turbulent dynamic coefficient. $\varepsilon$ is the turbulent kinetic energy dissipation rate, the relationship between them is

$$
\varepsilon=C_{D} \frac{k^{3 / 2}}{l} .
$$

Laminar turbulent kinetic energy is generated by the velocity gradient; the expression is

$$
G_{k}=\mu_{t}\left(\frac{\partial u_{i}}{\partial x_{j}}+\frac{\partial u_{j}}{\partial x_{i}}\right) \frac{\partial u_{i}}{\partial x_{j}} .
$$

$G_{b}$ of buoyancy turbulent kinetic energy is generated; the expression is

$$
G_{b}=\beta g_{i} \frac{\mu_{t}}{\sigma T} \frac{\partial T}{\partial x_{i}}
$$

for turbulent sticky factor, the expression is

$$
\mu_{t}=\frac{c_{\mu} \rho k^{2}}{\varepsilon} .
$$

(4) Meshing. CFD meshing software usually follows the following principles.

(a) A grid cell to another grid cell expansion coefficient ratio is generally maintained between 2 and 5; the critical areas should be smaller.

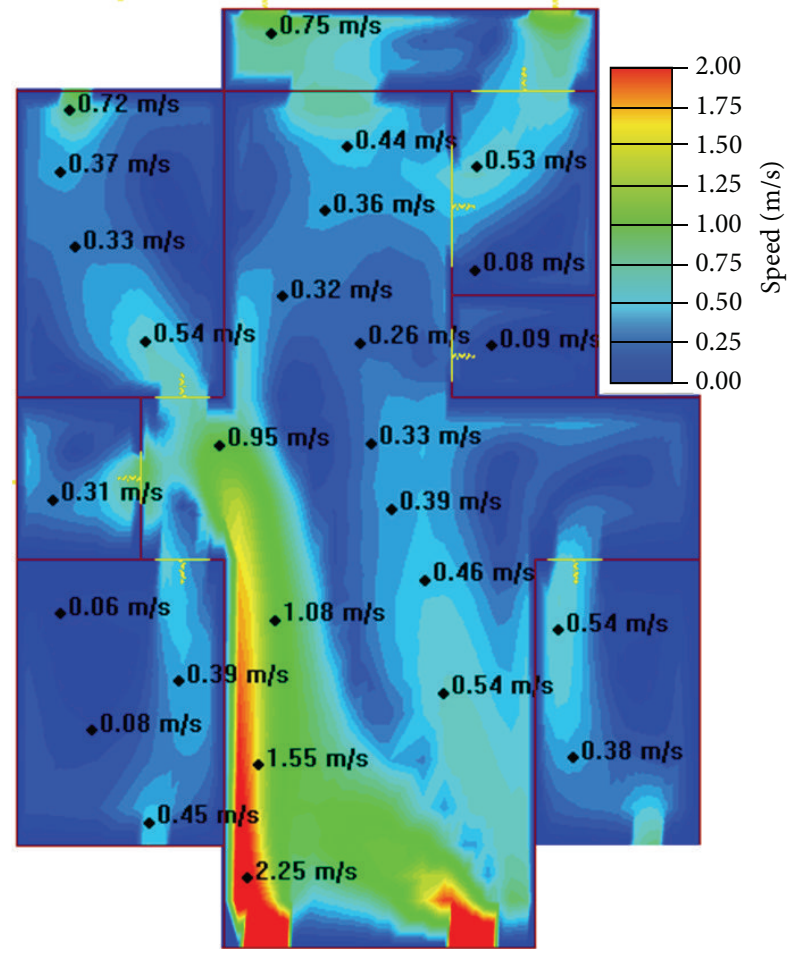

FIGURE 9: The wind speed distribution of the wind angle $\alpha=45^{\circ}$.

(b) The preferred shape of the grid cell is a regular hexahedron or tetrahedron.

(c) A coarse mesh should be used in the place where temperature gradient and velocity gradient are small. However, mesh refinement should be used in the place where temperature gradient and velocity gradient are very big.

3.1.2. Physical Model. In this paper, the simulation object is located in a residential district in Shenyang city, and it is seven layers of ordinary residence; its total construction area is $1669.18 \mathrm{~m}^{2}$. Every floor has two households, and the height of each household is $3 \mathrm{~m}$. The function layout of every room is the same with an apartment layout (see Figure 4). In the simulations, we headed for the building of the south as the prototype of simulation, and the model simplified in the premise of indoor thermal characteristics is not missing, as shown in Figure 5.

3.2. The Setting of the Simulation Conditions. This paper has studied the impact of the wind angle (see Figure 6) on buildings' energy consumption. Wind angle $\alpha$ is the angle between the normal outdoor environment wind and the normal direction of inlet plane (building surface). When the flow is perpendicular to the surface of the building, $\alpha$ is $0^{\circ}$, and when the flow is parallel to the surface of buildings, $\alpha$ is $90^{\circ}$. As provisions, the clockwise direction is positive and the counterclockwise direction is negative. The angles are shown in Figure 6. 


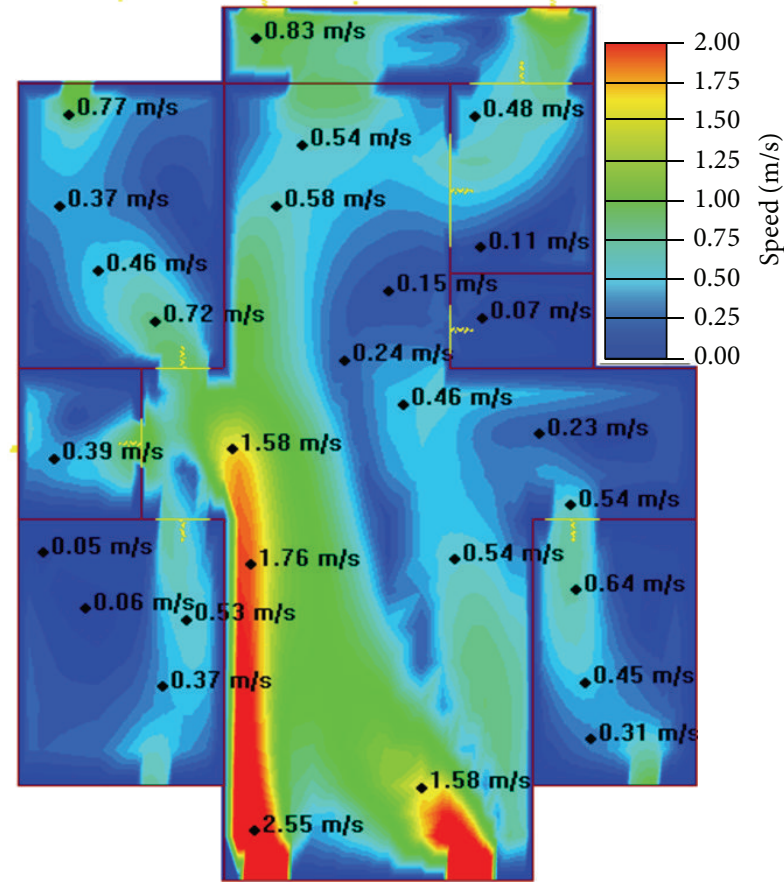

FIGURE 10: The wind speed distribution of the wind angle $\alpha=30^{\circ}$.

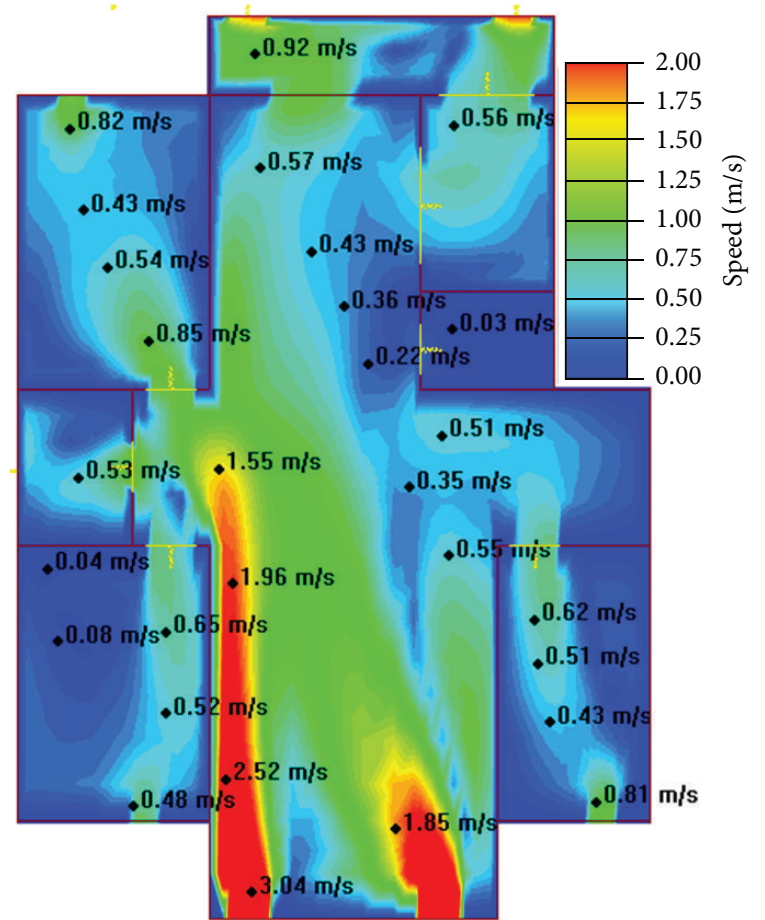

FIgURE 11: The wind speed distribution of the wind angle $\alpha=15^{\circ}$.

During the simulation, the released heat of the indoor human body, lighting and equipment, and uptime of the air conditioner has been a unified set. In order to obtain comparable data in the simulation, we have chosen buildings mainly facing south. The change factor in the simulation model is the

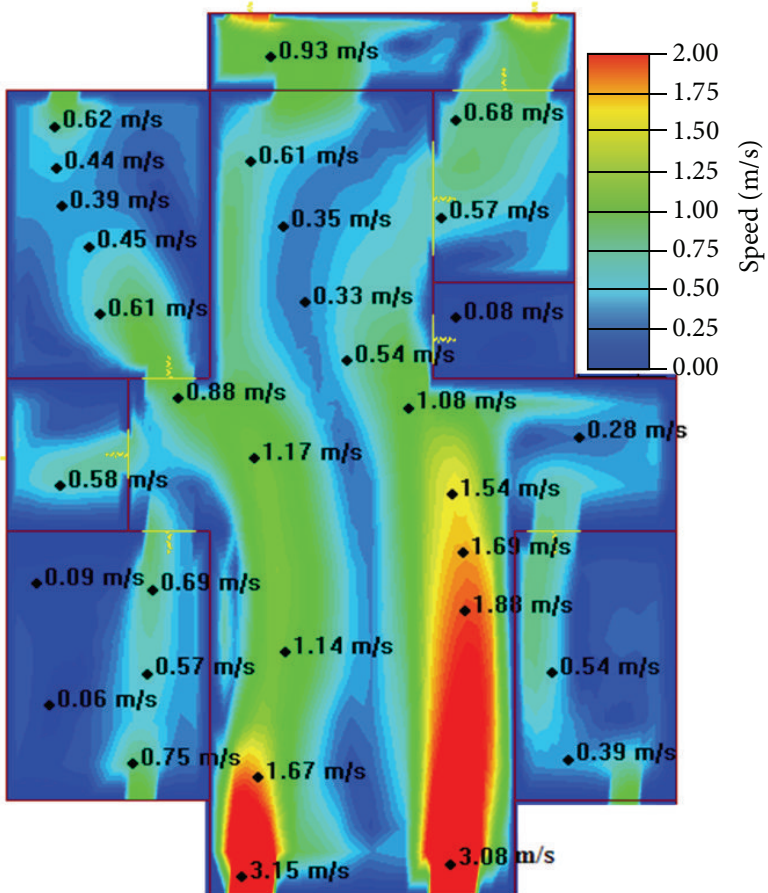

FIGURE 12: The wind speed distribution of the wind angle $\alpha=0^{\circ}$.

wind direction angle which, respectively, includes $0^{\circ}, 15^{\circ}, 30^{\circ}$, $45^{\circ}, 60^{\circ}$, and $75^{\circ}$.

(1) The Settings of the Indoor Disturbance. In the numerical simulation of the residential indoor thermal environment, the indoor heat productivity is usually replaced by three heat resources, the human body, equipment, and lighting [18]. The form of the three heat sources affecting the indoor environment is not the same. The moisture gain process is usually accompanied with the release of the latent heat, directly affecting the indoor air and improving the enthalpy of the indoor air.

The released sensible heat of the human body, equipment, and lighting, on one hand, can be transmitted to the surrounding air in the form of convection. On the other hand, the heat can be transmitted to the indoor objects in the form of radiation and then the heat is transmitted from the object surface to the surrounding air by convection heat [19]. As all the residential building functions are basically the same and the indoor heat productivity is comparatively stable during the research process, the representative data of the heat inside the residential buildings can be obtained through the method of investigation.

Combining the building structure, the building layout, room function, family structure, and the number of people, a Tsinghua professor Yiwen [20] summarized four residential patterns, as shown in Table 1. After statistically analyzing the indoor heat survey data under four residential patterns, we can get hourly variety of the human body, lighting, and equipment under different modes.

The third residential mode is used in this paper. Father, mother, and child are in the family. There are no more than 2 
TABLE 1: The residential construction and personnel structures under different modes.

\begin{tabular}{lcccc}
\hline \multirow{2}{*}{ Residential patterns } & Mode 1 & Mode 2 & Mode 3 & Mode 4 \\
& Two rooms one hall & Two rooms one hall & Pager & Pager \\
& Double bedroom & Double bedroom (PC) & Double bedroom & Double bedroom (PC) \\
& Study (PC) & Single bedroom & Single bedroom & Double bedroom \\
Rooms feature & Living room, dining & Living room, dining & Study (PC) & Single bedroom \\
& Kitchen & Kitchen & Living room, dining & Living room, dining \\
& Toilet & Toilet & Kitchen & Kitchen \\
Family structure & - & - & Toilet & Toilet \\
\hline Number of people & Couples & Parents and children & Parents and children & Spouses, parents, and children \\
\hline
\end{tabular}

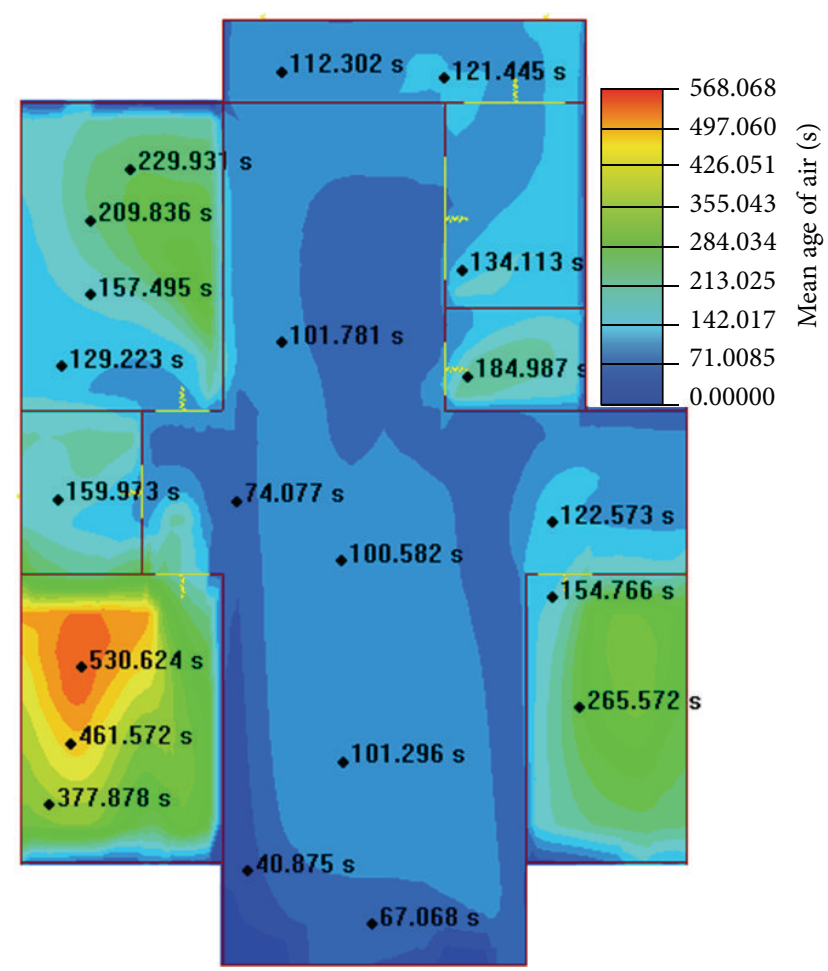

FIGURE 13: The distribution of average air age of the wind angle $\alpha=$ $75^{\circ}$.

people in the master bedroom, no more than 1 person in the second bedroom, and no more than 3 people in the living room. The calorific value for one person in the room is $53 \mathrm{~W}$. The largest calorific value of lighting, devices in living room, and devices in kitchen is $5 \mathrm{~W} / \mathrm{m}^{2}, 9.3 \mathrm{~W} / \mathrm{m}^{2}$, and $48.2 \mathrm{~W} / \mathrm{m}^{2}$, respectively [21]. Changes of parameters are in Table 2.

(2) Air Condition Parameters Settings. Air conditioners and heating devices would affect the indoor thermal environment conditions. When room temperature is higher (higher than body's tolerable temperature), people would turn on air conditioners to adjust the room temperature and humidity in summer. In other words, people would turn on air

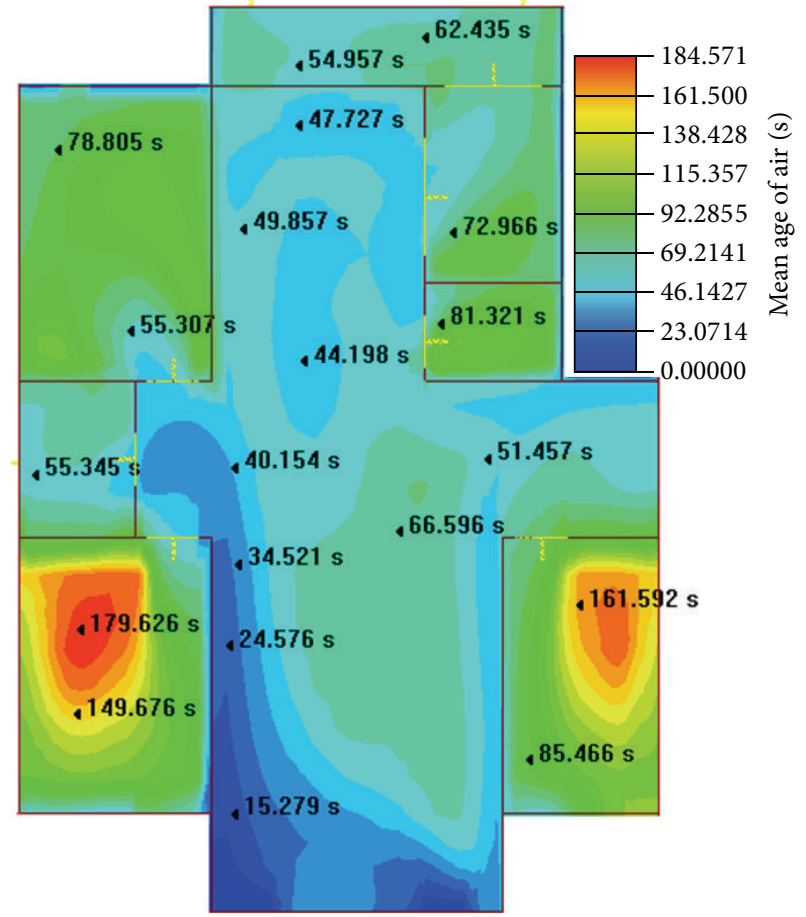

FIGURE 14: The distribution of average air age of the wind angle $\alpha=$ $60^{\circ}$.

TABLE 2: Time table of indoor people, lighting, and devices in cold regions.

\begin{tabular}{lccc}
\hline Room & Bedroom & Living room & Kitchen \\
\hline Lighting & $22: 00 \sim 23: 00$ & 19:00 22:00 & $\begin{array}{c}7: 00 \sim 8: 00 \\
18: 00 \sim 19: 00\end{array}$ \\
\hline Devices & All day is 0 & 19:00 23:00 & $\begin{array}{c}7: 00 \sim 8: 00 \\
18: 00 \sim 19: 00\end{array}$ \\
\hline People & \multirow{2}{*}{ 22:00 7:00 } & 19:00 22:00 & $\begin{array}{c}7: 00 \sim 8: 00 \\
18: 00 \sim 19: 00\end{array}$ \\
\hline
\end{tabular}

conditioners when the temperature is higher than the tolerable temperature rather than the desired temperature. It is found in the investigation that requirement of the thermal comfort cannot be satisfied by natural ventilation when room 


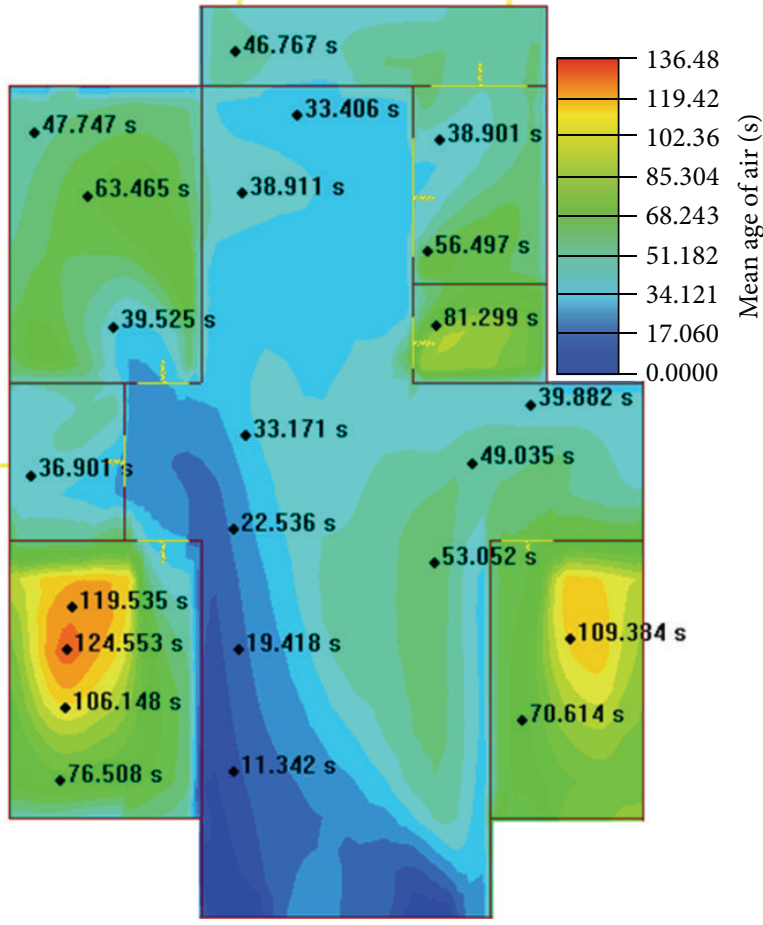

FIGURE 15: The distribution of average air age of the wind angle $\alpha=$ $45^{\circ}$.

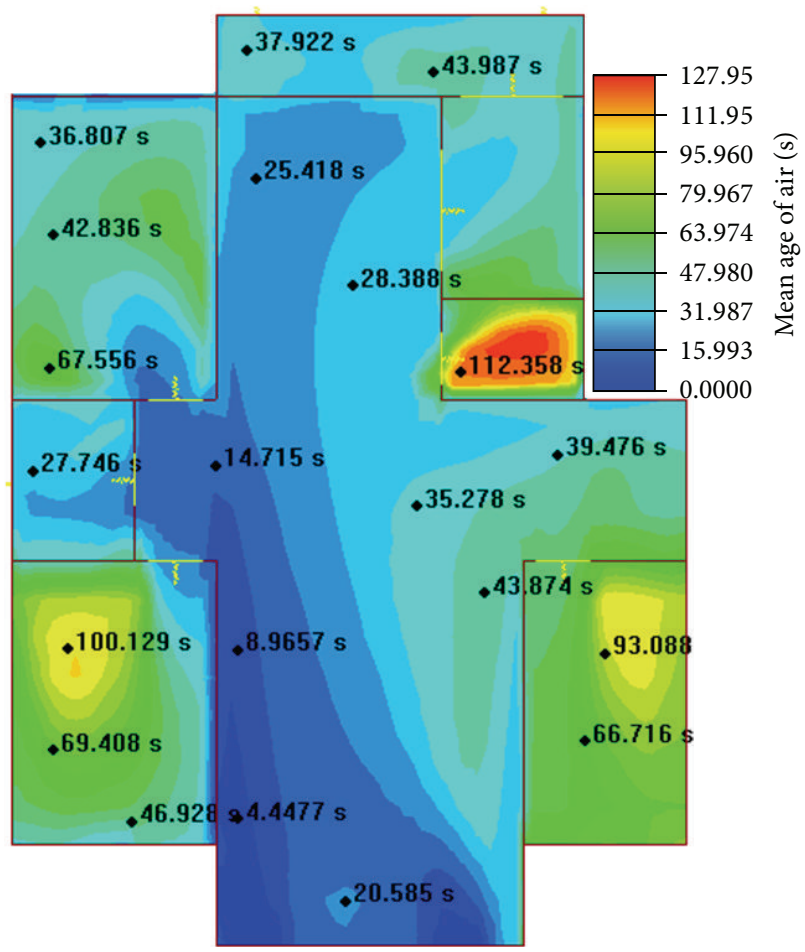

FIGURE 16: The distribution of average air age of the wind angle $\alpha=$ $30^{\circ}$.

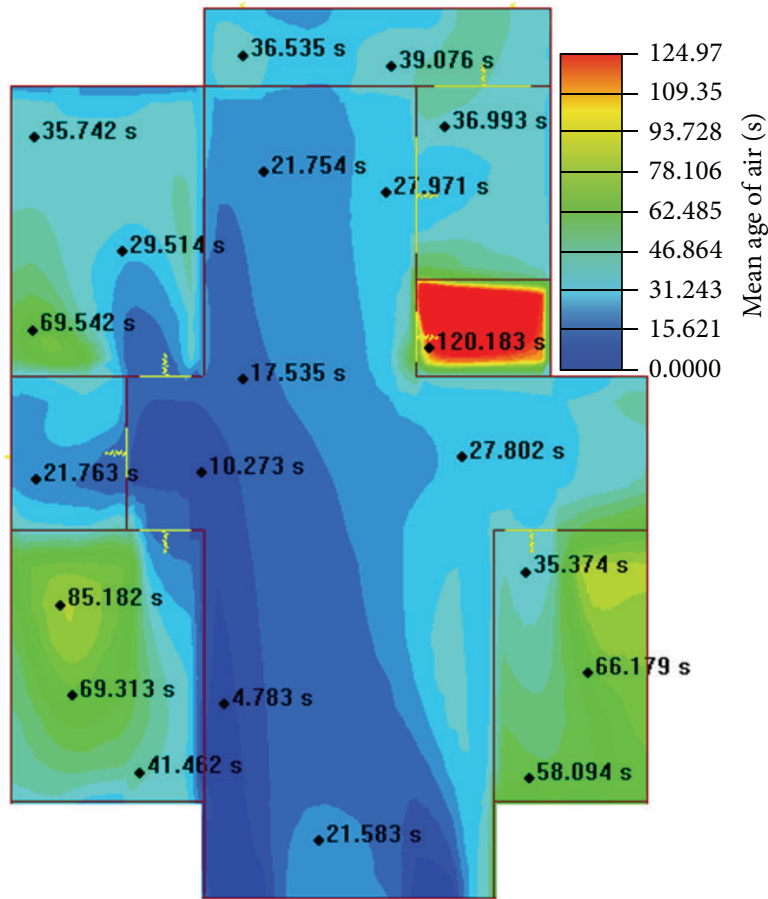

FIGURE 17: The distribution of average air age of the wind angle $\alpha=$ $15^{\circ}$.

temperature is $16^{\circ} \mathrm{C} 28^{\circ} \mathrm{C}$ [20]. Mechanical ventilation as an auxiliary is needed. So, the controlling temperature of indoor air conditioners is $26^{\circ} \mathrm{C}$. Refrigeration is used in July and August. The tolerant temperature ceiling is $28^{\circ} \mathrm{C}$ (to determine whether to turn on air conditioners or not). Heating is used from December 1 to March 31. The controlling temperature of indoor heating is $18^{\circ} \mathrm{C}$. The ventilators' rate is set from 0.5 times/h to 5 times/h.

\section{Analysis of Effects of Natural Ventilation under Different Wind Angles}

Laws of wind angles affecting natural ventilation are derived through the analysis of the effects of natural ventilation under different wind angles. And they would provide guidance on design of residential building orientation.

In the process of natural ventilation, the wind direction of outdoor environment will change complicatedly. To make better use of natural ventilation, when designing residential buildings, the paper keeps an appropriate wind direction angle of incidence between the local dominant wind direction in summer and the residential building. The dominant wind direction in summer in Shenyang is southwest. But the orientation of conventional residential design is almost south or north. South orientation is used as the standard in the process of simulation. The variable factor of the simulation is wind angle which would be $75^{\circ}, 60^{\circ}, 45^{\circ}, 30^{\circ}, 15^{\circ}$, and $0^{\circ}$.

The influence of wind speed at human height and air age distribution on human body is considered in the analysis of indoor ventilation's effects. So, velocity field at $1.1 \mathrm{~m}$ height 


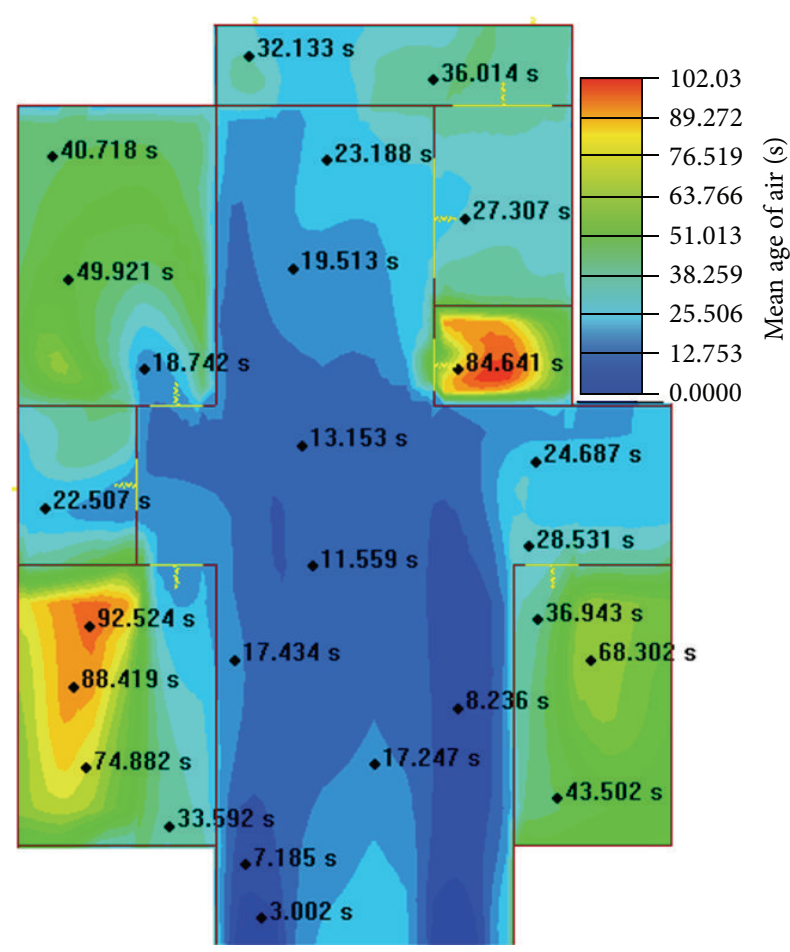

FIGURE 18: The distribution of average air age of the wind angle $\alpha=$ $0^{\circ}$.
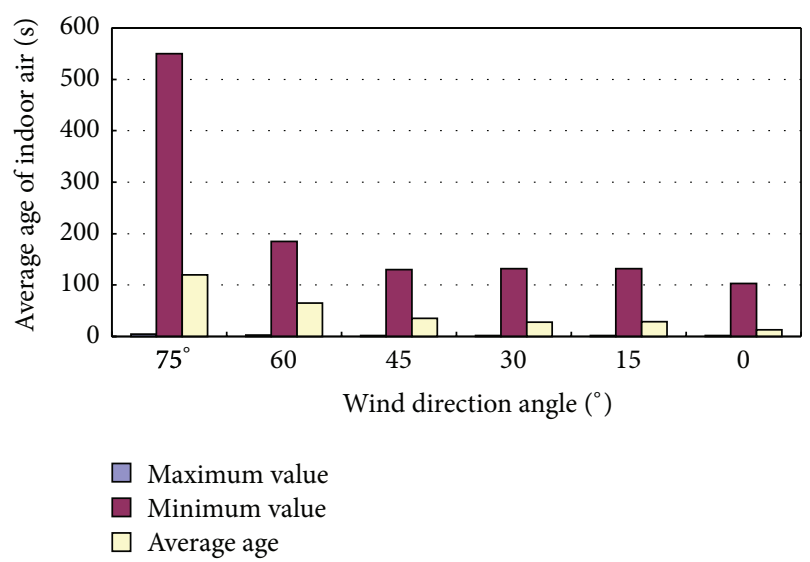

Figure 19: The contrast figures of average age of indoor air under different working conditions.

[22] (an average sitting person's nose height from the ground) and average air age field are chosen to be objects of study.

(1) Wind Velocity Distribution under Different Wind Angles. When outdoor air enters building through the opening in the surface, a velocity field will form in the interior. In the case of the same speed and direction of the outdoor wind and different outdoor wind angles, indoor velocity distribution differs. Figures 7, 8, 9, 10, 11, and 12 show airflow velocity distribution contours of $75^{\circ}, 60^{\circ}, 45^{\circ}, 30^{\circ}, 15^{\circ}$, and $0^{\circ}$ wind angles at $1.1 \mathrm{~m}$ height (an average sitting person's nose height from the ground).
The distribution of indoor velocity field under different wind angles shows that (a) when the outdoor air flows into the interior space, large or small vortex will form. Under the action of vortex, outdoor fresh air enters into the room, while the polluted air is exhausted to the outside along with the air flow; (b) air enters into the interior through the opening at the building's windward side and flows out of the window opening of the leeward side. Air flow is affected by diversion of the walls in the process of the interior flow. The direction of part of the air flow will change. The air flow rate is higher on the main path in the air circulation; (c) wind angle varies from $75^{\circ}$ to $60^{\circ}$ and then changes to a $45^{\circ}$ angle. Change in the magnitude of the angle of each interval is not much, but the distribution of the indoor velocity field has changed a lot. With the decrease of the wind angle, indoor whirlpool forms clearly and spreads to most of the interior space. It is indicated from the phenomenon that, in the case of larger wind angle, small change in the angle will cause larger effects on distribution of the indoor flow field; (d) when the wind angle varies from $0^{\circ}$ to $30^{\circ}$, indoor cross-ventilation can form obviously. Wind speed is larger in the rooms and there is no wide range of ventilation blind spot. When the wind angle is greater than $45^{\circ}$, indoor wind speed will decline rapidly. The range of indoor ventilation blind spot will increase gradually. It is disadvantageous to eliminate polluted indoor air by use of ventilation and the indoor ventilated effect is poorer.

(2) The Distribution of Age of Indoor Air under Different Wind Angles. Figures 13, 14, 15, 16, 17, and 18 show the distribution of the average age of indoor air at $1.1 \mathrm{~m}$ height (an average sitting person's nose height from the ground) in the cases of different wind angles. Color in the picture transfers from the cool tone to the warm tone. The color represents the average age of indoor air. The cool tone means that the age value of air is small. That means it needs a shorter time to complete the replacement under the condition of natural ventilation and fresh air is better; on the contrary, the warm tone means that the age value of air is large, and it needs a longer time to complete the replacement under the condition of natural ventilation and the fresh air is poorer.

The distributions of indoor average air age of different wind angles are shown in Figures 13, 14, 15, 16, 17, and 18, they show that (a) in the case of larger wind angle, the value of indoor average air is generally higher. With the decrease of the wind angle, the average age of indoor air in the same area will significantly reduce and the degree of fresh air will increase, which improves the indoor air quality. (b) Because there is no outside window in the small indoor toilet, effective air convection cannot form. Almost no wind flows into the room and the airflow velocity is small. Thus, the average age of air is relatively bigger here than that in the other rooms. The fresh air is bad, so we need to use auxiliary ventilation through the mechanical approach in this region. (c) Under the predominant wind direction in summer, the ventilation blind spot will form in the master bedroom and in some areas of the residential study room. With greater wind angles (except $0^{\circ}$ ), the range of ventilation blind spot will be larger. 

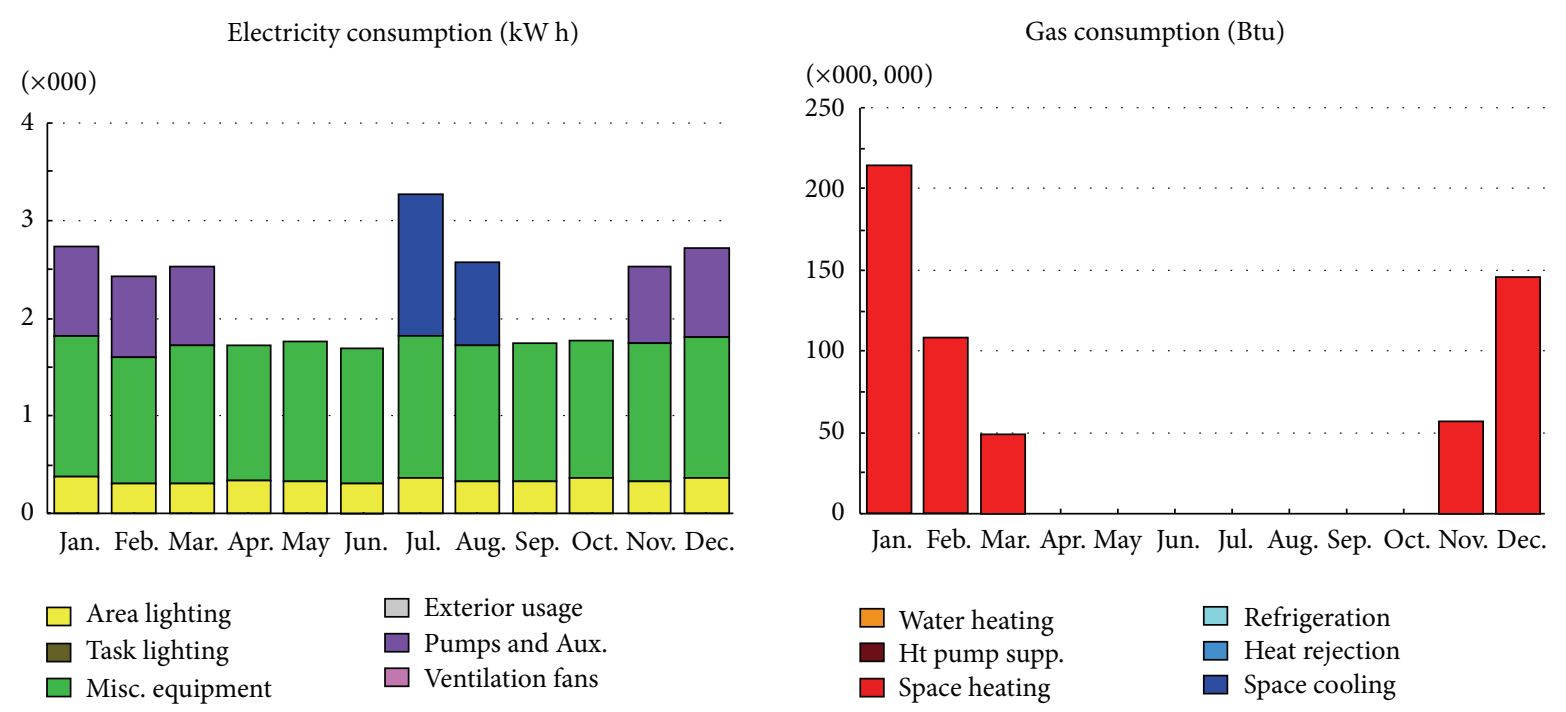

FIgURE 20: The residential energy consumption distribution when the wind angle is $0^{\circ}$.
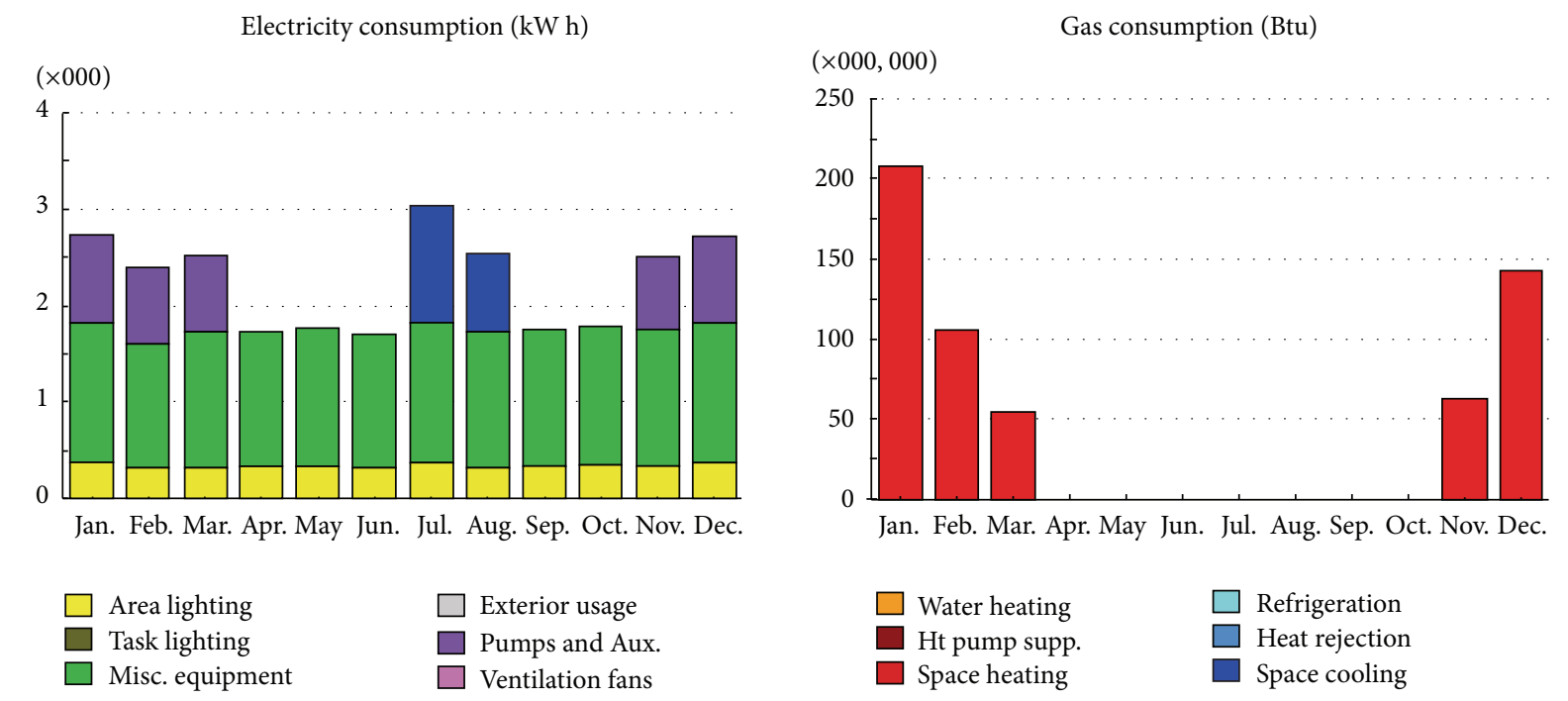

FIGURE 21: The consumption distribution of the residential energy when the wind angle is $15^{\circ}$.

By the comparison analysis of average age of indoor air under the different wind angles in Figure 19, it can be seen that wind angle gets greater; the average age of indoor air will be bigger. When wind angle is $0^{\circ}$, the average age of indoor air will be the minimum and the fresh air will be the best. When the range of wind angle varies from $15^{\circ}$ to $45^{\circ}$, the change of the average age of indoor air will not be much. It is basically stable within the range and the indoor air quality is relatively good.

In residential space, people mainly focus on the indoor environment of the bedroom, study, and living room (people stay there for a long time). People (male or female) mainly stay in these residential rooms, so whether indoor environment in these rooms is good or bad is directly related to the indoor personnel health. When we consider the indoor wind speed and the distributions of the air age in the case of different wind angles, it can be concluded that the indoor ventilation effect is better when the wind angle varies from $0^{\circ}$ to $45^{\circ}$.

\section{Residential Building Energy Simulation Analysis Performed under Different Wind Angles throughout the Year}

According to the predefined lifestyle and air conditioning operation mode, we use EQUEST software to perform residential building energy simulation analysis under different wind angles throughout the year. Figures 20, 21, 22, 23, 24, and 25 show the annual 
Electricity consumption $(\mathrm{kW} \mathrm{h})$

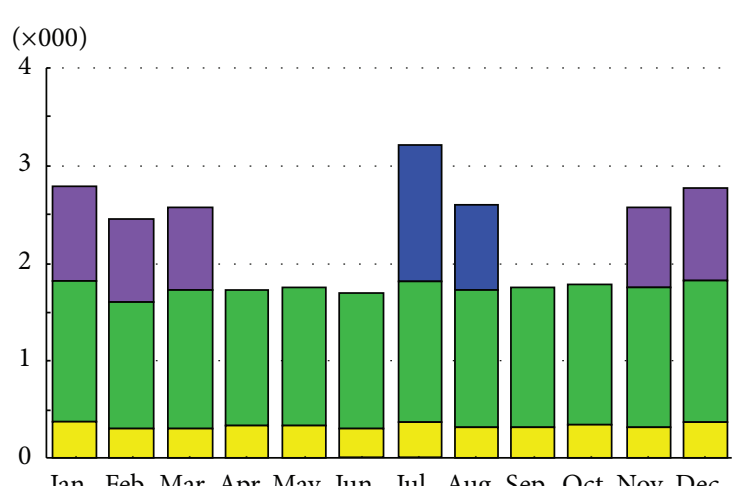

Jan. Feb. Mar. Apr. May Jun. Jul. Aug. Sep. Oct. Nov. Dec.

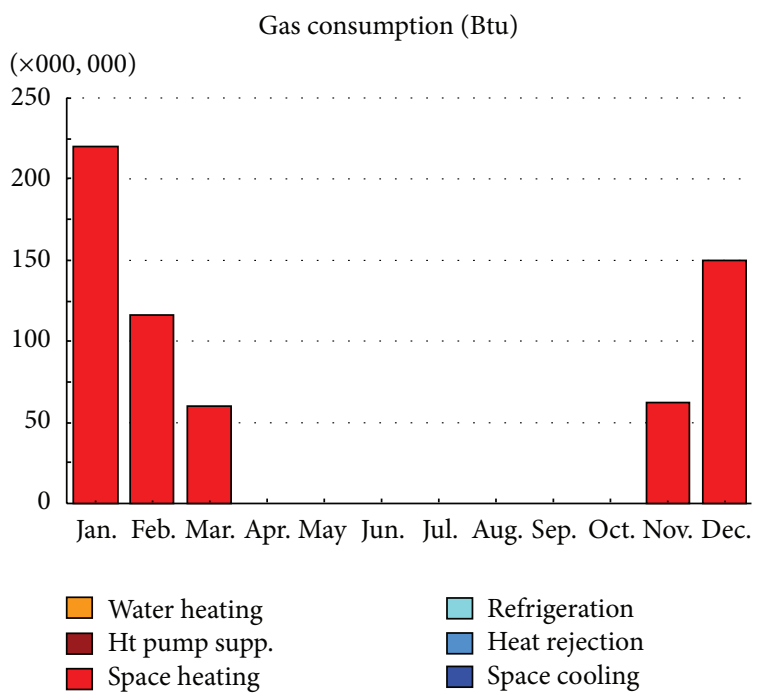

Figure 22: The consumption distribution of the residential energy when the wind angle is $30^{\circ}$.
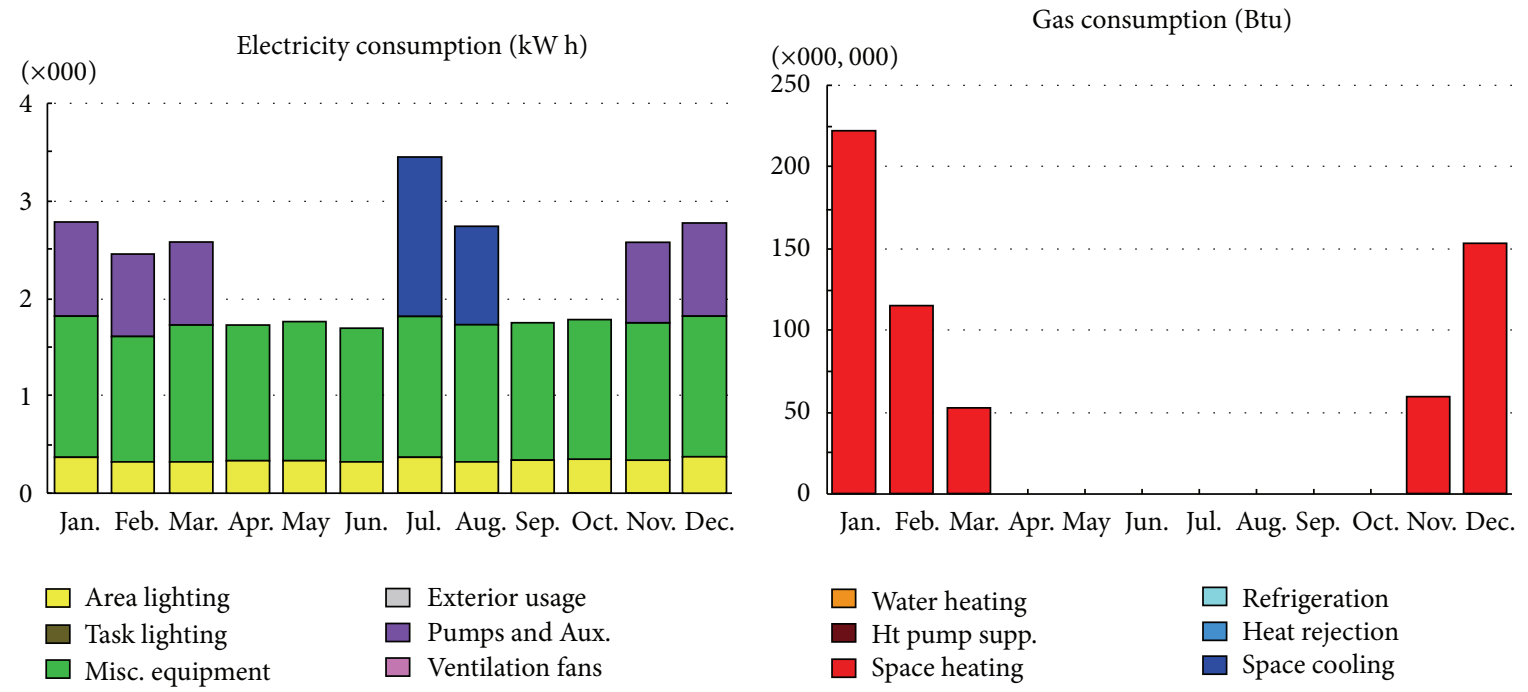

FIGURE 23: The consumption distribution of the residential energy when the wind angle is $45^{\circ}$.

energy consumption values of the residence under different conditions. During the period of residence in the running, energy is supplied by electricity and gas. In order to facilitate uniform comparison, the results are converted into a unified dimension $\mathrm{KJ}$; the specific conversion method is $1 \mathrm{KWh}=3600 \mathrm{KJ}, 1 \mathrm{Btu}=1.06 \mathrm{KJ}$.

Figure 20 shows the residential energy consumption distribution when the wind angle is $0^{\circ}$. Obviously, comprehensive energy consumption of the residence includes the energy consumption of lighting, household appliances, air conditioning, and heating. When the wind angle is $0^{\circ}$, residential power consumption throughout the whole year is $27000 \mathrm{KWh}$ (i.e., $97.2 \mathrm{GJ}$ ); the gas consumption for heating is $5.19 \times 10^{8}$ Btu (i.e., $\left.571 \mathrm{GJ}\right)$. Comparing energy consumption of each month, they show that (1) consumption in winter and summer is higher than that in transition seasons, and energy consumption in the hottest month of July and the coldest month of January is higher than that in other months within the same seasons, respectively. (2) In individual energy consumption, power consumption of devices and energy consumption of residential interior lighting are almost the same each month. (3) In the process of annual energy consumption simulation, the energy consumption of residential heating mainly occurs during the period from December to February and rarely in November and March. During the period from November to January, it increases with the decrease of outdoor temperature. During the period from February to March, it reduces along with the rise of outdoor 

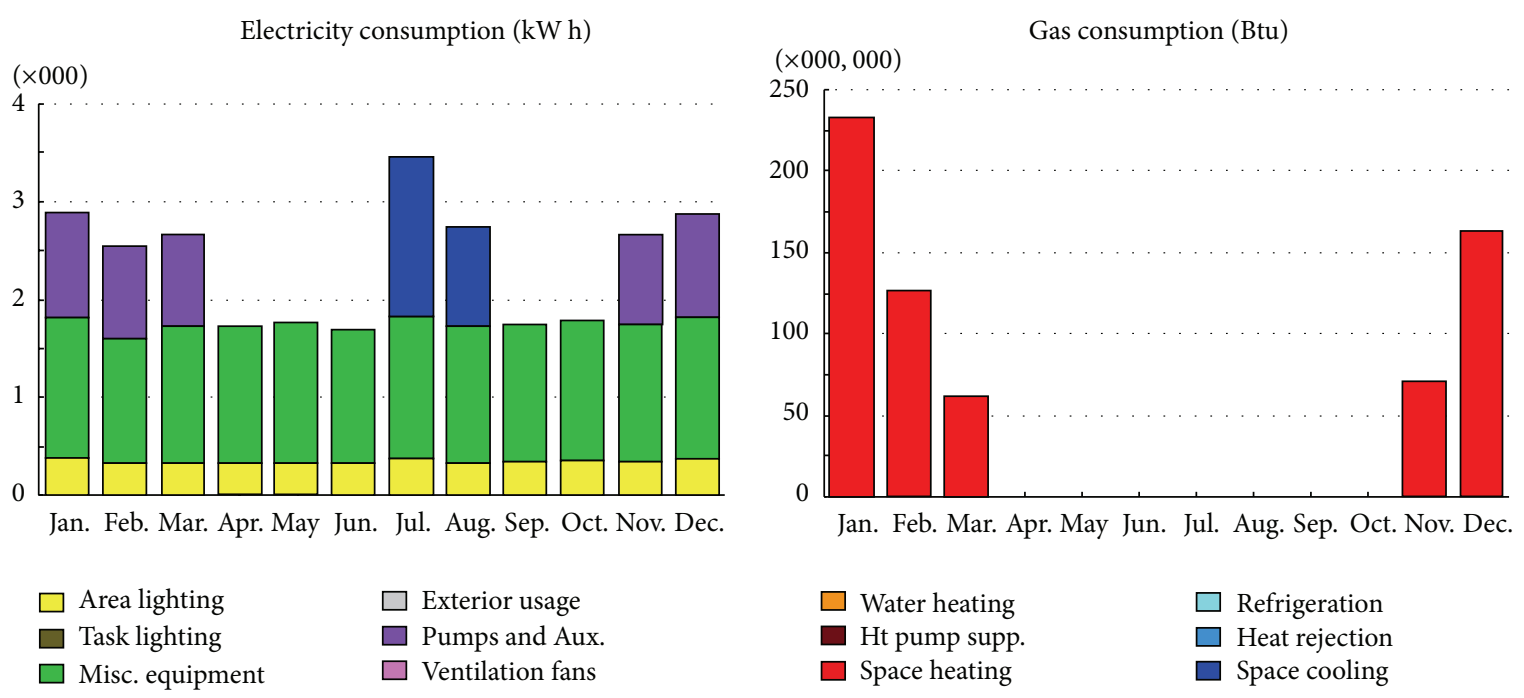

FIgURE 24: The consumption distribution of the residential energy when the wind angle is $60^{\circ}$.

temperature. The energy consumption of air conditioning mainly occurs in July and August and rises with the decrease of outdoor temperature.

The accumulation of electricity consumption and the gas consumption under different angles will be drawn into the chart months, as shown from Figures 26 to 28 .

Figures 26 and 27 show the comparison of the residential energy consumption of each month under different wind angles. The changes in building orientation mainly affect building heating and energy consumption of air conditioning and have almost no effect on energy consumption in transition seasons. Because the building orientation affects both the solar radiation's heat gain and the infiltration's heat loss, the heat gained from solar radiation in summer will increase the cooling energy consumption of air conditioning, but in winter it will reduce the energy consumption of heating.

Figure 28 shows the effect of the wind direction angle on comprehensive energy consumption of buildings throughout the year. It can be seen that when the building rotates in the positive direction, the comprehensive energy consumption of the building throughout the year presents a parabolic trend. When the wind direction angle is $15^{\circ}$, the comprehensive energy consumption of building is the minimum, 652.3 GJ. As the wind direction angle increases gradually, the yearly comprehensive energy consumption of the building increases gradually. This shows that the appropriate orientation of building should be south or $15^{\circ}$ south by west. Being affected by the changing rule of the solar altitude angle and the azimuth angle, the building facing south or near south can make full use of solar energy, and the solar radiant heat is large, so the heating energy consumption can be reduced accordingly. While the dominant wind direction of Shenyang is north or northeast, the building facing south or near south can avoid the dominant wind direction in winter and reduce the amount of cold air penetrating. As a result, the heat loss of residential rooms reduces. In summer, the architectural sunshine area is small when the building is facing south or near south. So, the solar radiant heat is relatively low. As a result, the yearly comprehensive energy consumption of the building is less when the building is facing south or near south.

\section{Conclusion}

(1) This paper analyzes the influence of wind direction angle for residential indoor natural ventilation on the typical model of a residential district in Shenyang through CFD numerical simulation. According to the study of indoor air velocity and air age distribution on different wind direction angles, when the wind direction angle ranges from $0^{\circ}$ to $45^{\circ}$, crossventilation will be formed. The wind velocity is large in the room, so the room does not have a wide area of ventilation dead corner basically and the average value of indoor air age is short, which means better freshness of the air. When the wind direction angle is larger than $45^{\circ}$, indoor wind velocity drops rapidly. The ventilation dead corner increases gradually; this is not beneficial for eliminating indoor polluted air by natural ventilation. Therefore, when the wind direction angle is from $0^{\circ}$ to $45^{\circ}$, the effect of the indoor natural ventilation is better.

(2) This paper has studied the energy consumption of the residence with different wind direction angles through EQUEST software. The conclusions are as follows.

(a) In the simulation process of yearly energy consumption, the energy consumption of residential heating in Shenyang is mainly concentrated from December to February, rarely 


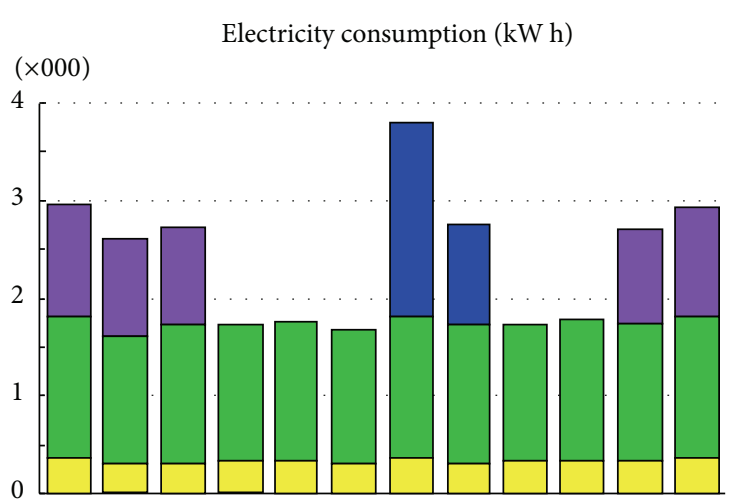

Jan. Feb. Mar. Apr. May Jun. Jul. Aug. Sep. Oct. Nov. Dec.

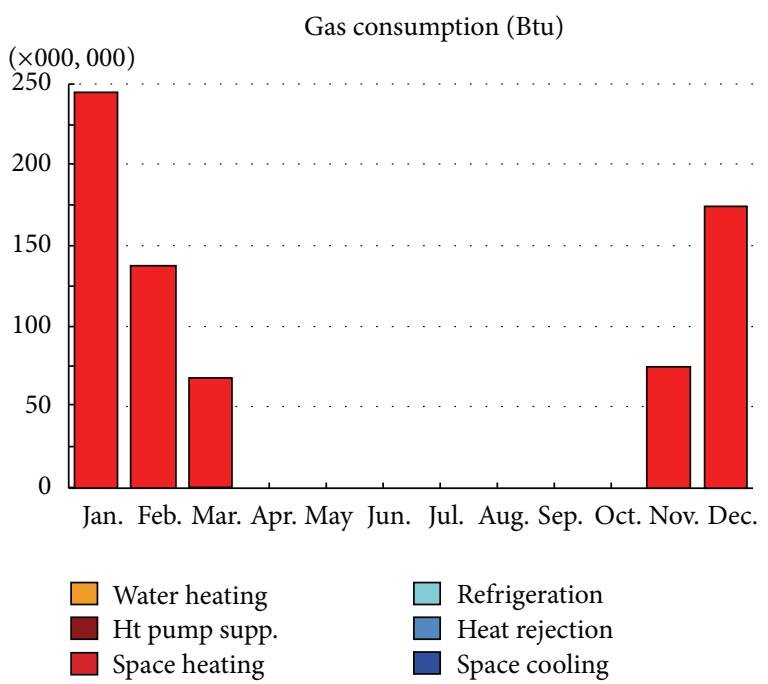

FIgURE 25: The consumption distribution of the residential energy when the wind angle is $75^{\circ}$.

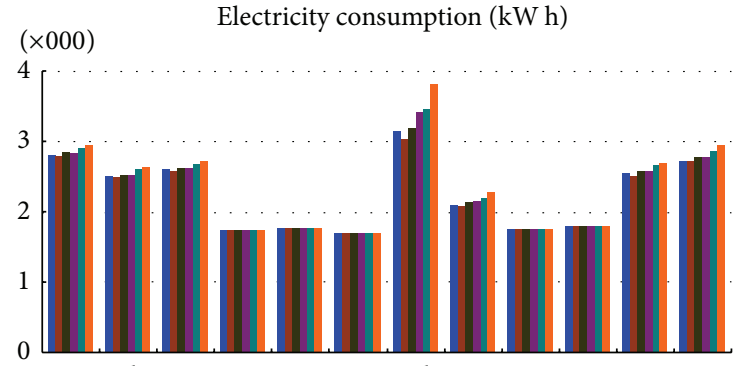

Jan. Feb. Mar. Apr. May Jun. Jul. Aug. Sep. Oct. Nov. Dec.

$$
\begin{aligned}
\alpha & =0^{\circ} & & \alpha=45^{\circ} \\
\alpha & =15^{\circ} & \alpha & =60^{\circ} \\
\text { a } & =30^{\circ} & \alpha & =75^{\circ}
\end{aligned}
$$

FIGURE 26: The comparison of the residential power consumption of each month under different wind angles.

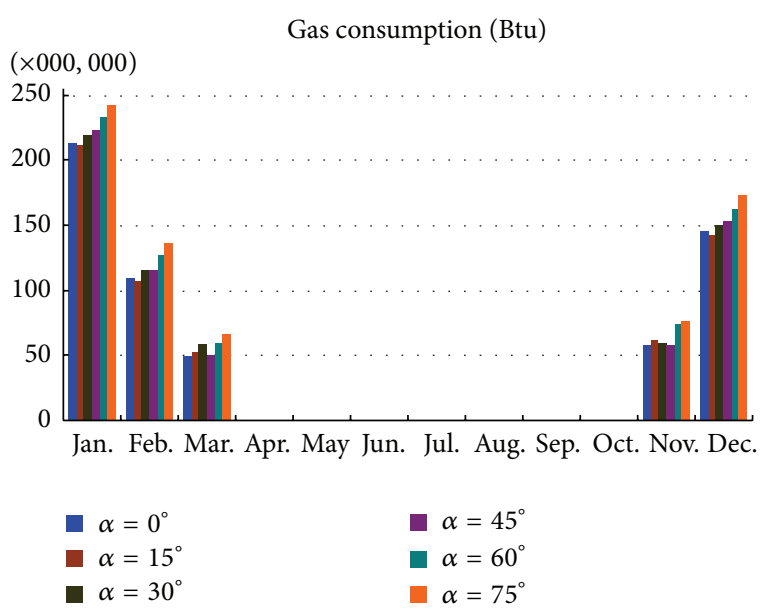

FIGURE 27: The comparison of the residential gas consumption of each month under different wind angles.

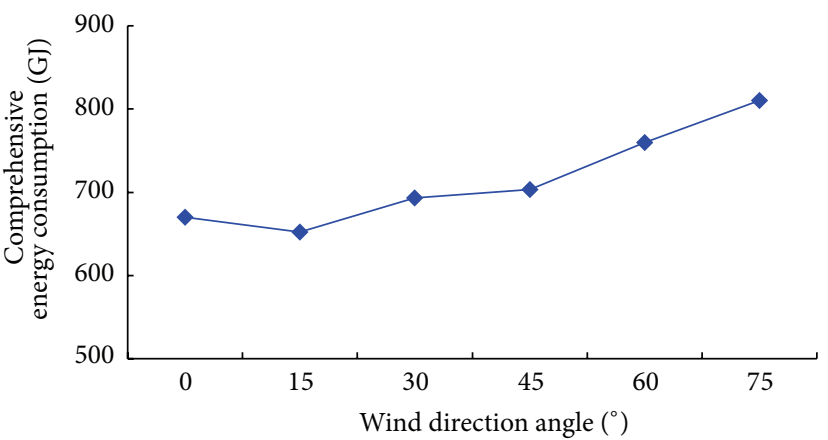

FIGURE 28: The comprehensive energy consumption of residence each year under different wind angles.

in November and March; during the period from November to January, the energy consumption increases with the decreasing outdoor temperature. The energy consumption of air conditioning is mainly concentrated in July and August and rises as the outdoor temperature decreases.

(b) Changes in the building orientation mainly influence residential heating and energy consumption of air conditioning and have almost no effect on the energy consumption of transition season.

(c) When the wind direction angle of buildings is from $0^{\circ}$ to $45^{\circ}$, the comprehensive energy consumption of buildings is relatively stable, which is a relatively favorable building orientation. Among all the angles, when the wind 
direction angle is $15^{\circ}$, the comprehensive energy consumption of building is the lowest. So, in terms of energy saving, the orientation should be the best solution in architectural design in Shenyang.

\section{Conflict of Interests}

The authors declare that there is no conflict of interests regarding the publication of this paper.

\section{Acknowledgment}

The authors acknowledge the support of the China Ministry of Housing and Urban-Rural Construction Research Project "Study on the regulation strategies of heat and humidity environment in closed sheds in cold area," 2013 (2013-K1-55).

\section{References}

[1] The annual development report on China building energy saving, 2009.

[2] G. Bo, Y. Nanyang, and W. Lei, "The strategy forms and simulation analysis of natural ventilation," Building Energy Saving, vol. 264, no. 7, pp. 30-33, 2004.

[3] J. P. Liu, Architectural Physics, China Building Industry Press, Beijing, China, 2009.

[4] L. Yang, Climatic analysis and architectural design strategies for bio-climatic design [Ph.D. thesis], Xi'an University of Architecture and Technology, 2003.

[5] G. Hongliang, Study the Key Issues of Residential Areas Indoor Natural Areas Indoor Natural Ventilation, Harbin Institute of Technology, Shenzhen Graduate School, 2009.

[6] S. Duan, G. Zhang, P. Jianguo et al., "Development in research of natural ventilation," Heating Ventilating and Air Conditioning, vol. 34, no. 3, pp. 22-28, 2004.

[7] L. Chuanzhi, F. Guohui, and X. Shuo, "Research into impact of buildings of different height on wind-induced natural ventilation," Journal of Shenyang Jianzhu University (Natural Science), vol. 23, no. 4, pp. 625-630, 2007.

[8] G. Guangcai, L. Hongxiang, and L. Yuguo, "The application and research of natural ventilation," Building Energy and Environment, vol. 4, pp. 4-7, 2003.

[9] K. Zhang, L. Wang, and N. Ren, "Analysis on the natural ventilation design of residential buildings in Northern towns," Journal of Shenyang Jianzhu University (Social Science), vol. 13, no. 3, pp. 274-277, 2011.

[10] Z. J. Cai and T. Y. Long, Fluid Mechanics Pumps and Fans, China Building Industry Press, Beijing, China, 1997.

[11] Y. Lu, M. A. Zuiliang, and P. Zou, Heating Ventilation and Air Conditioning, China Building Industry Press, Beijing, China, 1997.

[12] L. Wang, B. Gong, and N. Yu, "The research of the thermal comfort in natural ventilation buildings," Journal of Harbin Institute of Technology, vol. 41, no. 12, pp. 254-258, 2009.

[13] W. A. Dalgliesh and D. Surry, "BLWT, CFD and HAM modelling vs. the real world: bridging the gaps with full-scale measurements," Journal of Wind Engineering and Industrial Aerodynamics, vol. 91, no. 12-15, pp. 1651-1669, 2003.
[14] W. Yin, Potential estimation and energy efficient evaluation of natural ventilation in building [Dissertation], Hunan University, 2009.

[15] W. Tao, Numerical Heat Transfer, Xian Jiaotong University Press, Xi'an, China, 2001.

[16] J. I. Woni, People, Climate, Building, China Building Industry Press, Beijing, China, 1982.

[17] B. E. Launder and D. B. Spalding, "The numerical computation of turbulent flows," Computer Methods in Applied Mechanics and Engineering, vol. 3, no. 2, pp. 269-289, 1974.

[18] Y. Wu, Numerical Simulation and Experimental Study on Interior Natural Ventilation of Residential Building, Tianjin University, 2009.

[19] Y. Wang and $\mathrm{Y}$. Wu, "On the improved evaluation of the residential indoor air quality with natural ventilation in cold weather," Journal of Safety and Environment, vol. 8, no. 5, pp. 104-108, 2008.

[20] J. Yiwen, The Research of Residential Thermal Performance Evaluation Method, Tsinghua University, 2003.

[21] ASHARE Standard 55-2002, Thermal Environmental Conditions for Human Occupancy, American Society of Heating, Refrigerating and Air-Conditioning Engineers, Inc., Atlanta, Ga, USA, 2002.

[22] S. Zhu, C. Qi, and W. Li, "Experimental research on thermal comfort of natural wind," Journal of Beijing Forestry University, vol. 29 , no. 4 , pp. 54-58, 2007. 


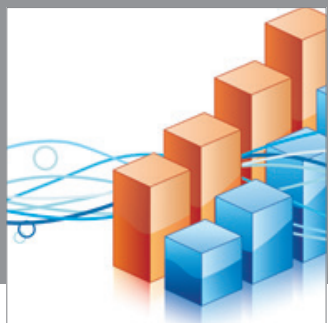

Advances in

Operations Research

mansans

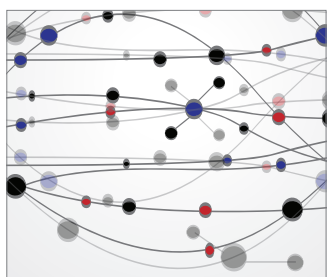

The Scientific World Journal
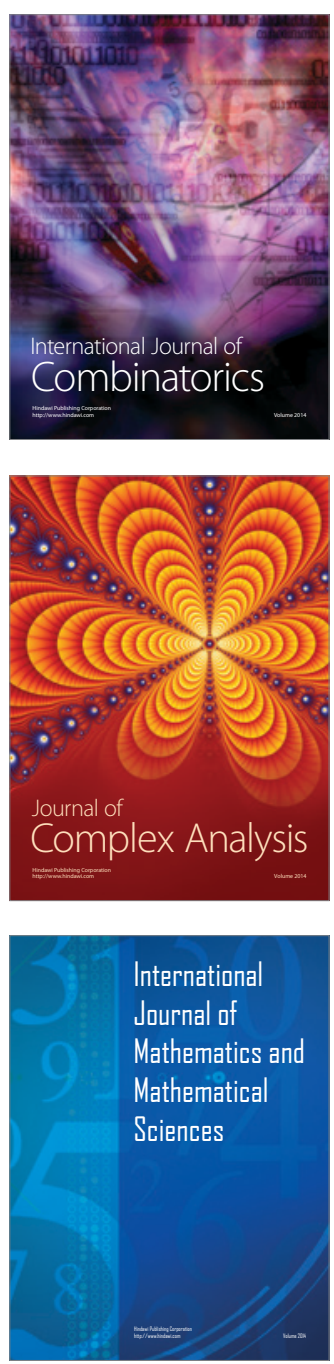
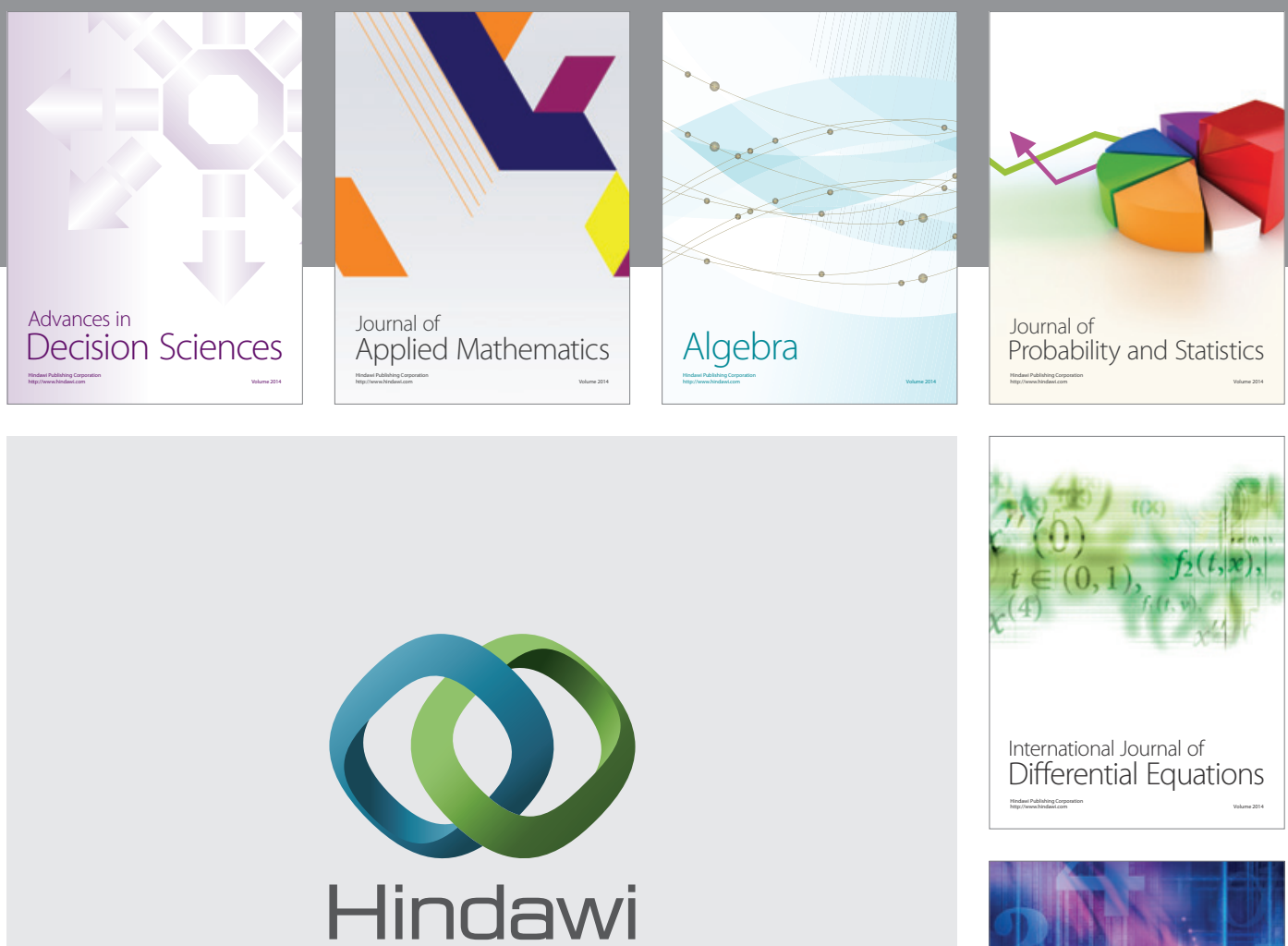

Submit your manuscripts at http://www.hindawi.com
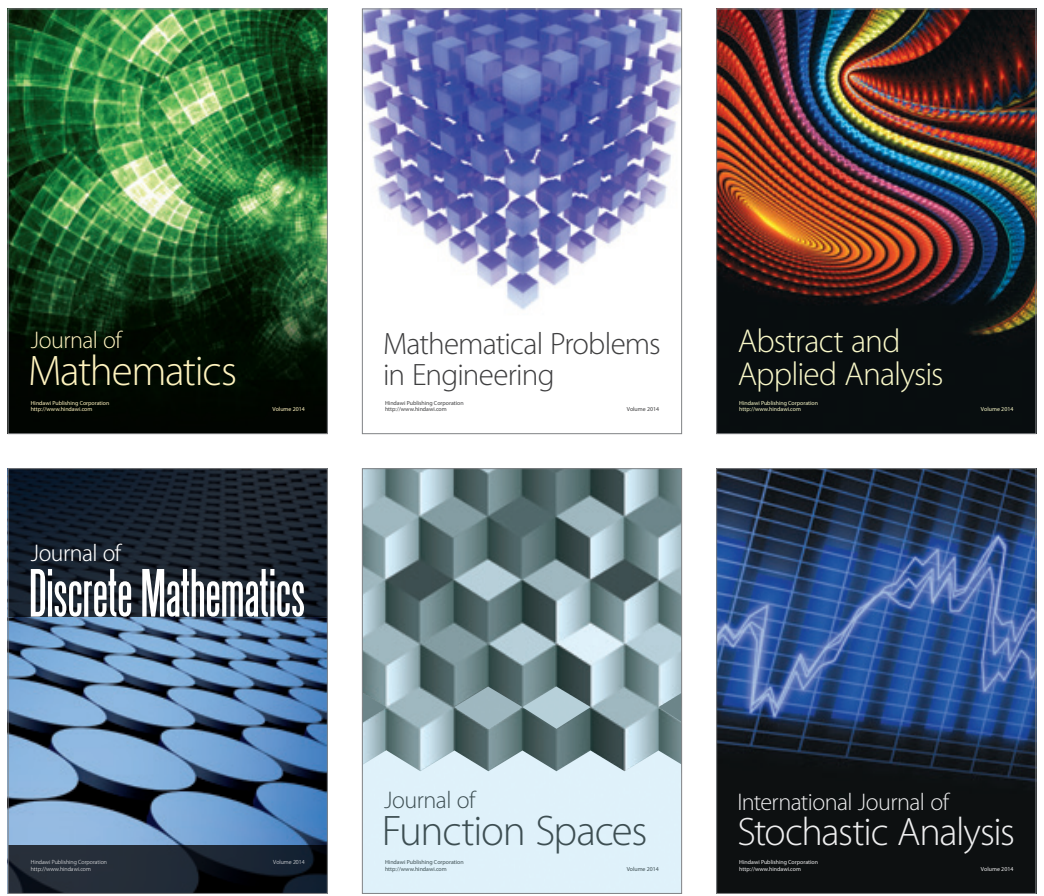

Journal of

Function Spaces

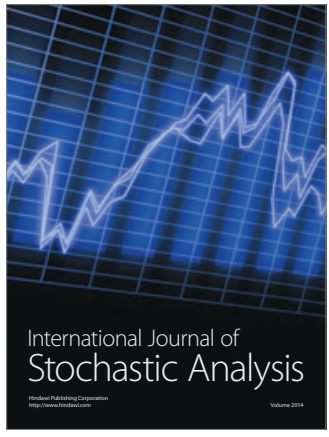

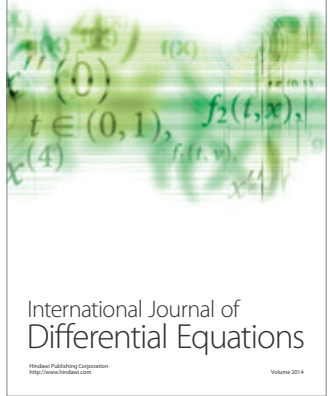
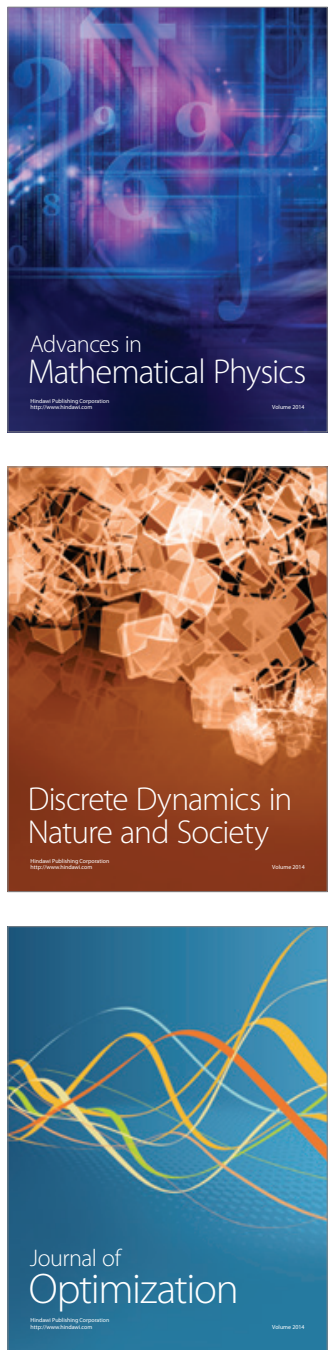